AFCRL 63-616

\title{
TIDE AND STORM SURGE OBSERVATIONS IN THE CHUKCHI SEA
}

\author{
Kenneth L. Hunkins
}

\section{LAMONT GEOLOGICAL OBSERVATORY COLUMBIA UNIVERSITY \\ Palisades, New York}

\section{Project No. 7628}

Task No. 762805

Scientific Report No. 7

Contract AF 19 [604] 7442

$$
\text { May } 1963
$$

\section{Prepared for}

Air Force Cambridge Research Laboratories Office of Aerospace Research

Bedford, Massachusetts 

AFCRL $63-616$

IIDE AND STORM SURGE OBSERVATIONS

IN THE CHUKCHI SEA

Kenneth L. Hunkins

Lamont Geological Observatory

Columbia University

Palisades, New York

Project No. 7628

Task No. 762805

Scientific Report No. 7

Contract AF 19 (604) 7442

May 1963

Prepared for

Air Force Cambridge Research Laboratories

Office of Aerospace Research

Bedford, Massachusetts 
Requests for additional copies by Agencies of the Department of Defense, their contractors, and other Government agencies should be directed to:

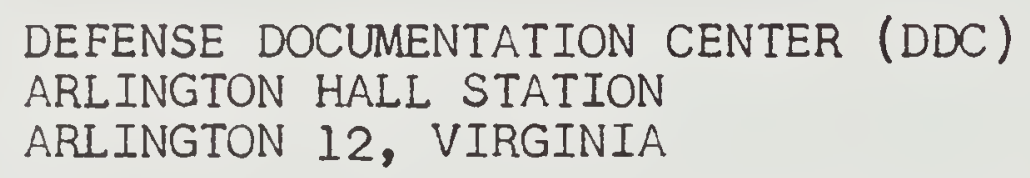

Department of Defense contractors must be established for DDC services or have their 'need-to-know' certified by the cognizant military agency of their project or contract. to the:

$$
\text { All other persons and organizations should apply }
$$

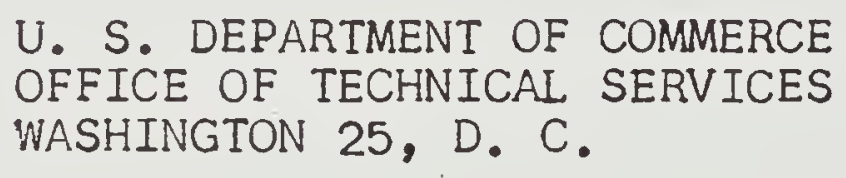


TIDE AND STORM SURGE OBSERVATIONS

IN THE CHUKCHI SEA

Kenneth L. Hunkins

Abstract.

Sea level heights were recorded with a tide gauge at Fletcher's Ice Island ( $T_{-} 3$ ) while it was aground in the Chukchi Sea at $71^{\circ} 55^{\prime} \mathrm{N}, 160^{\circ} 20^{\prime} \mathrm{w}$. Harmonic analyses were made for the tidal components. The tidal hour for $M_{2}$ is 9.11 at this location, in good agreement with the co-tidal chart of Sverdrup (1926).

Storm surges observed at this location on the continental shelf have a range of about $40 \mathrm{~cm}$. During relatively stationary atmospheric conditions, the storm surge heights can be interpreted as due to the static water barometer effect. During conditions of moving atmospheric pressure systems, storm surge heights differ from thosepredicted by tire water barometer effect. The combined application of Ekman's wind-driven current theory and Bernoulli's equation provides an explanation for these differences.

\section{Introduction}

A unique opportunity for sea level studies at an offshore location was presented in May 1960 when Fletcher's Ice Island ( $I_{-} 3$ ) became grounded on the continental shelf north of Alaska. The grounded location of the station, well offshore 
on the widest continental shelf in the world, was particularly suitable for tide and storm surge studies. The uniformity of water depth and the open situation away from coasts permit sea level changes to be studied without many of the usual complicating influences. Sea level heights were measured for about six weeks in 1961 with a tide gauge installed at the edge of $I_{-} 3$. The results of these measurements are reported and discussed in this paper. A few days of hourly sea level heights were also taken the previous year, 1960, by Gerry Cabaniss and David Craven. Their results have not yet been published.

T-3, which has been used extensively as a scientific research station, is an ice mass floating in the Arctic Ocean. It has been occupied intermittently since 1952. T-3 apparent. ly formed as shelf ice on the northern coast of Ellesmere Island, later breaking off to become a part of the drift ice of the Arctic Ocean. The ice is! and measures about $7 \times 12 \mathrm{~km}$ in horizontal dimensions and $50 \mathrm{~m}$ in thickness. It is considerably thicker than sea ice in the Arctic Ocean which averages only about $3 \mathrm{~m}$.

In early May 1960, while drifting near the northern coast of Alaska, T-3 went aground about $130 \mathrm{~km}$ west_northwest of Point Barrow. The following spring, when the measurements were made, T-3 was at $71^{\circ} 55^{\prime} \mathrm{N}$ latitude and $160^{\circ} 20^{\prime}$ longitude (Fig. 1). This location is at the eastern edge of the Chukchi Sea on the wide continental shelf which extends from the Taimyr Peninsula of Siberia to Point Barrow. Over most 
of the Chukchi Sea, depths vary between 40 and $60 \mathrm{~m}$. The Chukchi Sea is bounded on the west and southwest by Wrangel Island and Siberia, whose coasts are about 600 to $700 \mathrm{~km}$ from I-3's grounded position. South of T-3 the Chukchi Sea is bounded by Alaska; on the north, it is bounded by the edge of the shelf at about $100 \mathrm{~km}$ from I-3.

In early 1962, T-3 floated free of its grounded position and is now adrift again on the Arctic Ocean.

Method of Observation

Actual sea level heights above the bottom were measured with an anchored line through a hole in the ice. A standard water level recorder manufactured by W. \& L. E. Gurley was used. It was mounted on a wooden frame over a hole in the ice. The instrument was located on sea ice attached to the western edge of $\mathrm{I}$-3. The ice at the site was $2 \mathrm{~m}$. thick and the water was $37 \mathrm{~m}$. deep. A 3/16" steel cable was anchored to the bottom with a large weight and the other end of the cable was led over the recorder pulley to a small counterweight. As the ice rose and fell with sea level, the cable was drawn backwards and forwards across the pulley. Deflections on the record represent true sea level changes with neither exaggeration nor reduction. The record drum was clock-driven at $1 / 3$ inch per hour.

I-3 was evidently grounded at some distance from the recording site so that the edges of the ice island and the attached sea ice freely followed sea level by flexing or rock- 
ing motions. Differences between true sea level heights and the observations would arise if (1) the ice at the edge was not completely free to follow sea level, or if (2) the ice island made some horizontal movements at its grounded position. The first possibility was shown to be of negligible effect with results obtained with a staff tide gauge mounted in the ice hole. Any changes in water level on the staff tide gauge would indicate relative motion between the ice and water. No significant changes were noted during the period of observation and it is concluded that the ice moved freely with changing sea level. The second question cannot be answered completely, but certainly no large horizontal movements took place during the observation period. No deviations of the anchor cable from the vertical were noticed. However, after the observations were completed, horizontal movements occurred in which the anchor weight was dragged and changes in navigational position were noted. It appears that any movements from the grounded location were large and that no such movement took place during the observations. Further confidence in the reliability of the data is furnished by certain agreements between the tides at T-3 and those at Point Barrow, as well as by agreements between the atmospheric pressure effect and sea level at $T_{-} 3$. These verifications will be discussed later.

\section{Oceanographic Conditions in the Chukchi Sea}

Some information on sea water density, currents and ice cover is available. These parameters all affect the water movements which produce changes in sea level. 
Hydrographic stations were taken at I-3 in 1960 while it was grounded (Kusunoki, et al, 1962). The stations were taken one year prior to the sea level observations but at about the same location and at the same season. On May 16, 1960 , the water was of nearly uniform density from top to bottom. During June, fresh water runoff diluted the surface waters and, by June 30 , a steep pycnocline existed between 3 and $10 \mathrm{~m}$. Below this pycnocline, density increased only slightly with increasing depth.

Surface currents set generally westward in the vicinity of I-3's grounded position. During the two months prior to running aground, F-3 drifted westward at an average rate of about $4 \mathrm{~km} /$ day or $5 \mathrm{~cm} / \mathrm{sec}$. Another current sets northeast. ward along the northwestern coast of Alaska from the Bering Straits to Point Barrow. Sverdrup (1936b) concluded from the great differences in temperature and salinity which he found in the Chukchi Sea that "strong currents must frequently be met in this sea and that a rapid circulation of water takes place."

Ice coverage between the coast of Alaska and I-3 was 0.8 to 1.0 in June 1961 with some open water close to the coast. According to the Oceanographic Atlas of the Polar Seas (1958), most of the Chukchi Sea would be closely covered (0.8 to 1.0$)$ at this time of year. However, the atlas also shows that in an exceptionally open year, the entire southern half of the Chukchi Sea might have only 0.5 or less coverage. 
Results of Harmonic Analysis

Although short period oscillations were also observed on the records (Hunkins, 1962), only oscillations in the tidal period range are investigated here. Harmonic analyses were made for two intervals: a 23-day period from May 15 to June 7, 1961 and a 26-day interval from June 11 to July 7, 1961. Hourly values of sea level heigh for the two intervals are plotted in Figure 2.

Two different methods of harmonic analysis were used, both employing the IBM 7090 computer. The first method was based on the U. S. Coast and Geodetic Survey system which has been described by Schureman (1958). A digital computer program employing this method was written by Dr. John Kuo. This method was designed for either 15 or 29-day series. Hence, the intervals were divided into 15-day periods. The second method of harmonic analysis was a least squares technique developed and programmed for the digital computer by Dr. Yasuo Sato. The entire 23 and 26-day series were analyzed with this technique. Prior to the harmonic analyses, the static effects of atmospheric pressure on sea level were removed from the data. The pressure effect was computed according to the relation: a one millibar increase of atmospheric pressure produces a one centimeter depression of sea level.

Results of the harmonic analyses are presented in Table I. Amplitudes and phases of the various components are given together with information on form number, spring tide range and the tidal hour for $M_{2}$. The component, $M_{2}$, is reasonably 
well determined. $S_{2}, O_{1}$ and $K_{1}$ are less reliably determined. Little or no confidence can be placed in $\mathrm{N}_{2}$ for such a short record period; however, $\mathrm{N}_{2}$ is included for completeness. Harmonic constants at Point Barrow and Flaxman Island are also included for purposes of comparison.

Tides in the Arctic Ocean have been the subject of a number of papers (Harris, 1911; Sverdrup, 1926; Marmer, 1928; Fjedstad, 1936). The semi-diurnal tide wave is almost entireIy derived from the Atlantic Ocean. It enters the Arctic Ocean through the opening between Greenland and Spitzbergen, travelling as a progressive wave which crosses the Arctic Ocean in about 12 hours.

The propagation of the tidal wave is best studied by comparison of the tidal hours at various locations. The tidal hour is found by dividing the local epoch by 30 and adding the west longitude of the station expressed in time. A detailed chart of the semi-diurnal tidal wave in the Chukchi Sea was produced by Sverdrup (1926). His chart was based on both tide gauge and current meter measurements. He showed that the tidal wave approaches from the north in this area and that it has a rotary character. According to Sverdrup's chart, the tidal hour at $I_{-} 3$ should be almost exactly nine hours. This agrees well with the average tidal hour of 9.11 calculated from the I-3 observations. 


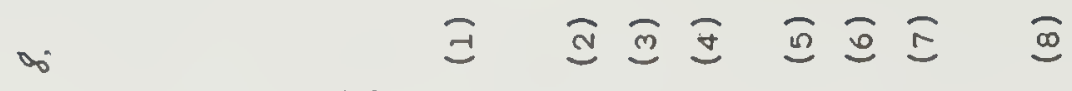

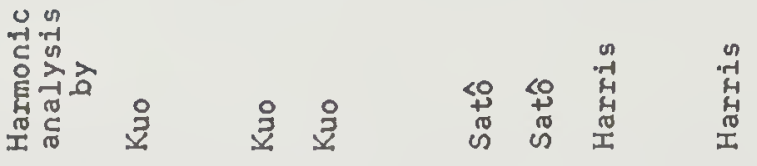

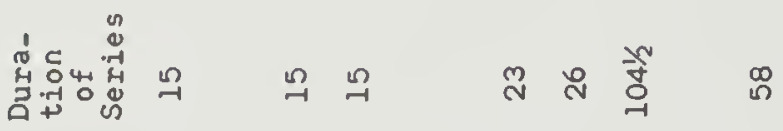

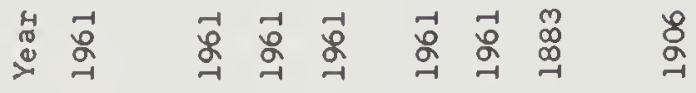

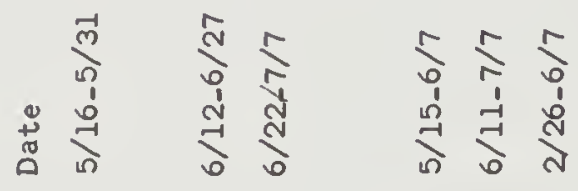

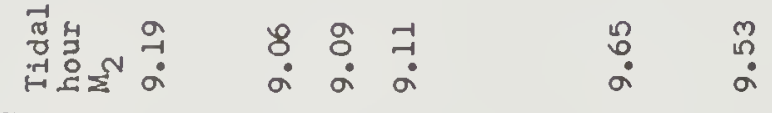

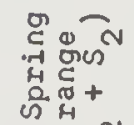

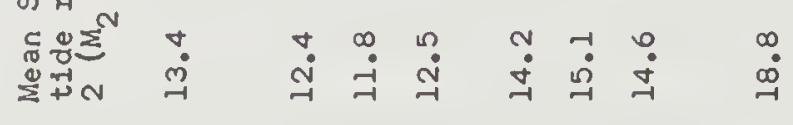

$$
\begin{aligned}
& \dot{2} 0^{-1}
\end{aligned}
$$

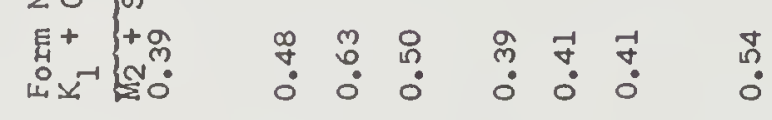

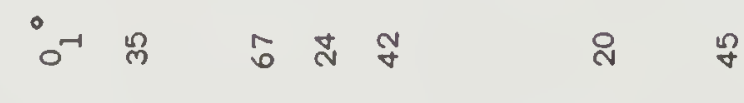

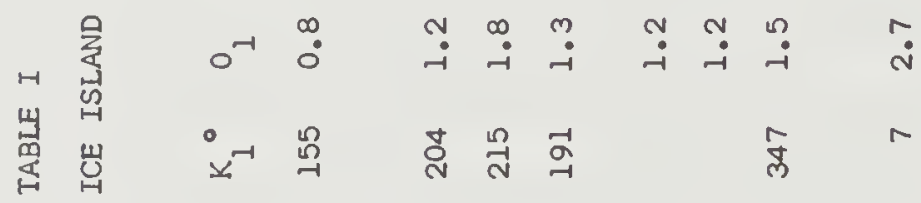

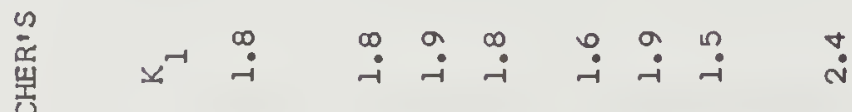

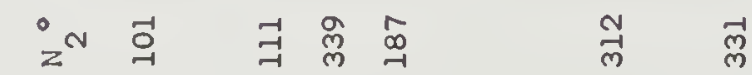

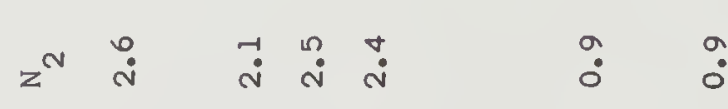

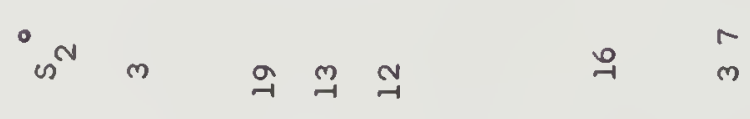

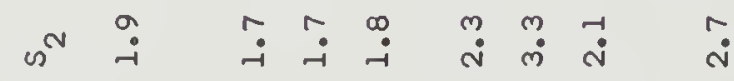

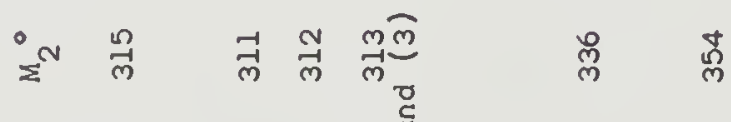

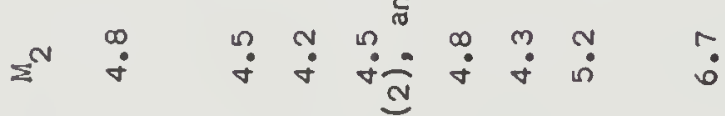

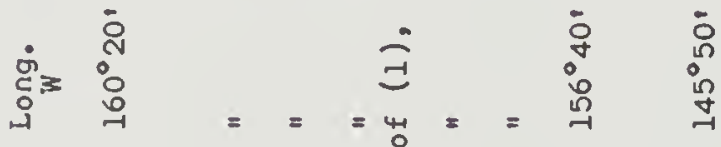

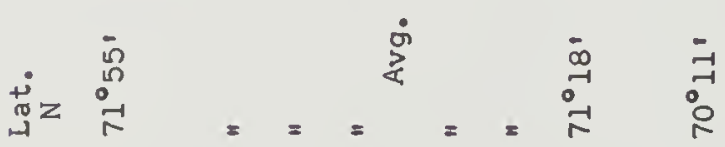

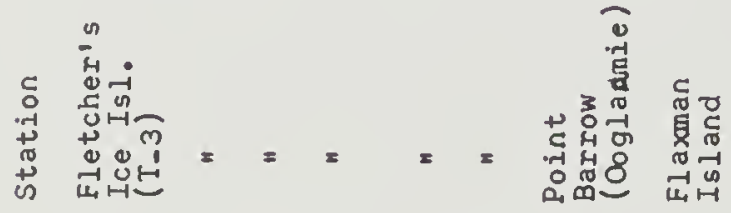

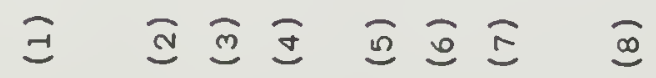




\section{Meteorological Effects}

Wind and pressure changes over the Chukchi Sea strongly influence sea level. Meteorologically-induced sea level changes extend over periods of several days and their amplitudes often exceed those of the tides. These meteorological effects can be seen most clearly after the tidal effects have been removed. Predicted tide values, based on harmonic synthesis, were subtracted from the observed sea level values to produce a residual curve. Tidal values used for the harmonic synthesis were taken from Satô's least squares harmonic analysis. The residual sea level heights, usually known as "storm surge heights," are plotted in Figures 3 and 4.

The storm surge heights can be explained to a large extent by the water barometer effect. Under static pressure conditions, and in the absence of wind, sea level would assume a shape dependent on the atmospheric pressure pattern over it. This is the water or inverted barometer effect which was used earlier in the harmonic analyses. This effect has been noted by many observers and it has usually been observed particularly clearly at sites where ice covers the ocean. Ross (1854), Wegener (1924), and Hessen (1932) have all found good correlation between sea level and the water barometer at ice-covered locations. Ross eloquently concluded from his study that "... the ocean is a water barometer on a vast scale of magnjficence." 
The water or inverted barometer effect at $\mathrm{T}-3$ is compared with storm surge heights in Figures 3 and 4 . Water barometer and wind values are shown for both $\mathrm{I}_{-} 3$ and Point Barrow. A certain general agreement between the water barometer and sea level indicates that the atmospheric pressure has an important influence on sea level at this location.

However there are notable differences between the water barometer and sea level curves on certain occasions. Significant differences can be seen on May 24-26, May 31-June 1, June 3-5, June 17-20, and July 6-7. Other differences between the two curves are present but the ones listed are the most prominent.

In each of the five cases, a rapidly moving atmospheric pressure system passed in the vicinity of $T$-3. Information on meteorological conditions is based on U. S. Weather Bureau surface charts for the northern hemisphere. The times of clos est passage to I-3 of the pressure centers are shown by vertical arrows in the figures. In Figure 3, the two pressure systems which passed $T_{-} 3$ were highs, while in Figure 4 , the two systems were lows. The origin of the fifth pressure system, a high on June 3-5, was not clearly shown on the charts and no arrow is shown for it. All four of the systems were travelling approximately northeastward at the time of their closest approach to T-3. After the passage of each of the two highs in Figure 3, sea level rose up to $12 \mathrm{~cm}$ above that predicted by the water barometer. After the passage of each of the two 
lows in Figure 4, sea level fell, $20 \mathrm{~cm}$ in one case and 10 in the other, below that predicted by the water barometer.

Relevant information on the four pressure systems is contained in Table II and synoptic surface charts are shown in Figures 5-7. The charts show conditions at time of closest passage and also the track of the center. The charts are based on a reasonably adequate number of weather stations in Alaska and Siberia but only occasional data from drifting stations NP_8 and Arlis II are available for the central Arctic Ocean. This is not a large handicap for the present study because conditions close to shore in the vicinity of $I_{-} 3$ are adequately described by the shore stations.

The high of May 24 developed north of Alaska and then moved north-northwest over the Arctic Ocean. The high of May 30 moved northwestward from Siberia across the Chukchi Sea (Figure 5). The center passed almost directly over T-3. The low of June 18 produced the most striking changes in sea level. This low moved northward over Siberia and Wrangel Island and out into the central Arctic Ocean (Figure 6). Another, weaker low moved eastward over the East Siberian Sea and then veered northward over Wrangel Island (Figure 7). A rapidly moving high travelled southwestward across the Arctic Ocean to Canada on June $3-5$ but its path and origin are probably not adequately described by the data. No further discussion of that particular one will be given. The significant fact is that a moving pressure system was associated with a 


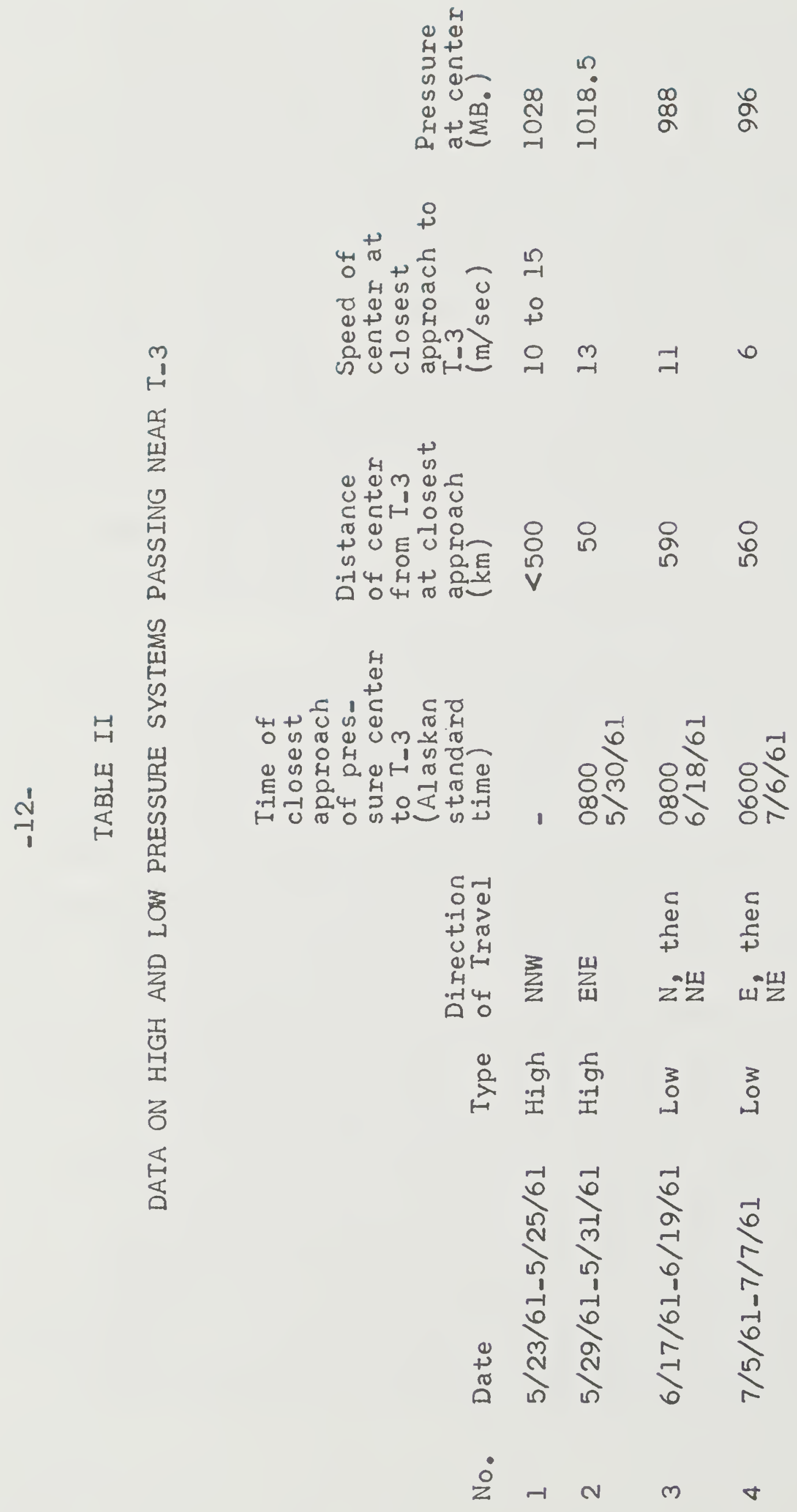


difference between the water barometer and observed sea level. The discussion will be limited to the systems for which the best data are available.

\section{Discussion of Storm Surges}

The nature of storm surges depends on many variables in the ocean and atmosphere. The factors which are considered important in this study are the following:

a. Water depth. Depths in the Chukchi Sea are fairly uniform at about $50 \mathrm{~m}$.

b. Velocity of freeprogressive waves. The relationship for long waves, $c^{2}=g h$, gives a velocity of $22 \frac{1}{2} \mathrm{~m} / \mathrm{sec}$ for the Chukchi Sea. However, the tide wave, which is travelling freely in this region, has a velocity of about $50 \mathrm{~m} / \mathrm{sec}$ due to its rotary nature (Sverdrup, 1926) and this velocity is probably more appropriate here since we are dealing with waves of nearly tidal period.

c. Velocity and direction of the pressure center. The pressure centers propagate with velocities between 6 and 15 $\mathrm{m} / \mathrm{sec}$ (see Table II), considerably slower than free wave velocities in this region. The pressure systems generally move at about one-fifth the velocity of free waves. The direction of travel is generally northeastward from Siberia across the Chukchi Shelf and into the central Arctic Ocean. d. Basin. configuration. Shelf width in the vicinity of $\mathrm{T}-3$ is about $250 \mathrm{~km}$. At the widest section, west of $\mathrm{T}_{-} 3$, the shelf is about $600 \mathrm{~km}$ wide. East of I-3, the shelf narrowo 
to about $50 \mathrm{~km}$ at Point Barrow.

e. Ratio of size of pressure system to basin size.

The pressure systems are in all cases several times as wide as the continental shelf.

f. Frictional effects. In shallow, ice-covered seas considerable turbulence is generated at both the bottom and at the underside of the ice. Hence, frictional effects are expected to be large in this situation. The relatively homogeneous water mass indicates that eddy viscosity must be large, with only slow changes in direction and velocity of the currents with depth.

g. Wind effects. The presence of pack ice increases the effect of wind on surface currents. Sverdrup (1936a) found that the ice in the East Siberian and Chukchi Seas drifted at an angle of $33.1^{\circ}$ to the right of the wind and with a velocity of 0.0177 relative to the wind. This wind factor is greater than that usually found for ice-free oceans.

The observed sea level heights may be explained as a combined result of three factors: (1) wind-generated currents, as influenced by the earth's rotation, (2) the propagation of the atmospheric pressure center, and (3) the water barometer effect. The interpretation is based on Ekman's theory of wind-generated currents (1905) in which he considered the influence of Coriolis force and turbulent friction, and on Bernoulli's equation for steady flow, which expresses the relation between current velocity, pressure and water height. 
Since these principles assume stationary conditions, it is necessary to examine this particular case to see if such conditions exist. It is likely that quasi-stationary motions are present in the wind-driven currents for it has been shown theoretically by Ekman (1905) that such currents are well developed in only a few hours. Quasi-stationary conditions must also exist for the atmospheric pressure effect. Since the pressure systems are propagating much more slowly than the velocity of long waves, the pressure effect must act quite rapidly. For simplicity, a one-dimensional section along the direction of storm propagation is considered. This is a natural way to study the phenomenon since the sea level record at a single station, such as I-3, gives a profile of sea level through the storm along the direction of propagation. The calculations are based on an idealized model of the moving low-pressure system of $6 / 17 / 61-6 / 19 / 61$. First the currents induced by the assumed wind field are calculated following Ekman's theory. Then Bernoulli's equation is used to find the sea level heights from the currents and pressure field.

A graphical section through the storm center along the direction of storm propagation is shown in Figure 8. The pressure field is given in the form of a water barometer curve. The wind field, shown in plan view by vectors, is symmetrical about the storm center and directed $30^{\circ}$ to the left of the isobars. The maximum wind velocity of $1000 \mathrm{~cm} / \mathrm{sec}$ is about the same as observed at T-3. The stress of the wind on the pack ice is assumed to move it at a 1/50 of the wind speed and $30^{\circ}$ to the right of the wind direction. The ice thus moves 
along the isobars. This assumption is in good agreement with many studies of ice drift and, in particular, it is close to Sverdrup's (1936) finding on the North Siberian Shelf. Sverdrup found a wind factor of 0.0177 and direction of $33.1^{\circ}$ to the right of the wind for ice drift. The deviation of the ice to the right of the wind direction is due to the effect of the earth's rotation expressed as the Coriolis force.

Just as the ice deviates to the right of the wind under the combined action of wind stress and Coriolis force, so does the water deviate to the right of the ice movement under the combined influence of stress due to the moving ice and Coriolis force. The ice acts as the immediate driving stress on the water in ice-covered oceans. Ekman's theory was developed for an open ocean of homogeneous water of unlimited extent. If the direction of ice movement replaces the wind direction in his theory it may be applied to ice-covered oceans. He shows that the surface water layer is deflected $45^{\circ}$ to the right of the wind in the northern hemisphere and that deeper layers are successively deflected further to the right, forming a descending logarithmic spiral. The wind-driven currents in this spiral occur withinthe "layer of frictional influence." Since this layer is usually about the same depth as the Chukchi Shelf, we may expect the spiral to be well-developed there. Sverdrup (1936b) in fact observed the Ekman spiral on the Chukchi Shelf with current meters. According to Ekman's theory, the total 
momentum of the current is directed $90^{\circ}$ to the right of the driving stress, the ice in our case. The theory refers to the angle between the relative motion of ice and water. The angle between the absolute ice movement and total current momentum will be somewhat less than $90^{\circ}$. The angle will also be affected by eddy viscosity and depth. Sverdrup's measurements show that $90^{\circ}$ is a fairly good approximation and this is the angle assumed in the model. The total water momentum along the section in Figure 10 is directed forward along the front of the storm and rearward along the rear of the storm. The average current velocity is assumed to be one-half that of the ice. This assumption is shown to be a reasonable one by Sverdrup's (1936b) current measurements on the North Siberian Shelf under density conditions similar to those at I-3.

With the current velocities and directions thus established, it is possible to apply Bernoulli's equation along the section to arrive at sea level heights. Bernoulli's equation is used in the form:

$$
p_{d} / p+\frac{1}{2}(v-\mu)^{2}+g \xi=C
$$

where,

$$
\begin{aligned}
& p_{d}=\text { atmospheric pressure } \\
& \rho=\text { water density } \\
& \mu=\text { current velocity } \\
& U=\text { storm propagation velocity } \\
& g=\text { acceleration due to gravity } \\
& \mathcal{Y}=\text { sea level height } \\
& C=\text { a constant }
\end{aligned}
$$


In order to apply the equation, a velocity to the left, $U$, equal to the storm propagation velocity, is impressed on the whole system. The storm then remains stationary and the water flows to the left beneath it. A value of $11 \mathrm{~m} / \mathrm{sec}$, as found for the storm of $6 / 17 / 61$ $6 / 19 / 61$, is assumed for $U$. Beneath the forward part of the storm, the wind-driven currents flow forward and are subtracted from $U$. This produces sea levels above equilibrium. Beneath the rear of the storm, the wind-driven currents flow backwards, adding their velocities to that of $U$. This produces sea levels below static equilibrium. The calculated sea level height is shown by the heavy line in Figure 8 . This interpretation is for shallow water since in deep water, compensation currents below the layer of frictional influence may tend to produce a return flow and reduce the sea level changes. For comparison, the observed storm surge height at T-3 is also shown in Figure. A detailed comparison is not warranted since I-3 was off the center line of storm propagation and the actual storm characteristics were generalized in the model. Nevertheless, a close similarity between the calculated and observed heights is apparent. The interpretation given here explains the heights which are above equilibrium levels beneath the forward part of the storm and below equilib. rium in the rear part of the storm. The same interpretation may also be applied to moving high-pressure systems to explain the exceptionally high levels beneath the rear part of the system. 
The explanation given here should be applicable to storm surge heights on shelves in other oceans. There is evidence on the Atlantic Coast for the same pattern of high water followed by low water beneath moving storm systems. In a report by Harris (1956), storm surge heights at various locations along the east coast of the United States are shown during the passage of two extratropical storms which travelled northward. At most of the stations a sea level pattern was observed similar to the one at T-3. Levels rose beneath the forward part of the storm and then, after the passage of the storm center, levels fell rapidly below normal sea level. These cases have not been studied in detail but it appears that the same explanation applies to these storms also. Storm surges must play an important part in mixing of water on the continental shelves. The sea level changes are accompanied by the trans. port of large volumes of water. In the future, detailed information from several offshore sites could be used to describe in detail the behavior of sea level beneath a travelling pressure system and further test the explanation given here.

Acknowledgments

The author is indebted to Henry Kutschale, James C. G. Walker, and Robert A. Page, Jr. who assisted in the operation of the tide gauge at $T_{-} 3$. This study was supported by the Air Force Cambridge Research Laboratories, 


\section{LIST OF ILLUSTRATIONS}

Figure 1 Grounded position of Fletcher's Ice Island (T-3) on the Chukchi Shelf. Depth contours in meters.

Figure 2 Sea level heights at Fletcher's Ice Island ( I-3). Based on hourly values taken from original records and referred to an arbitrary base value. $150^{\circ}$ meridian time.

Figure 3 Storm surge heights at Fletcher's Ice Island ( $T_{-} 3$ ) from $5 / 15 / 61$ to $6 / 7 / 61$ (heavy line). Inverted or water barometer at $\mathrm{I}-3$ and Point Barrow (light lines). Winds at $\mathrm{T}_{-}-3$ and Point Barrow (arrows). Large arrows indicate closest passage to $\mathrm{T}_{-} 3$ of two highs.

Figure 4 Storm surge heights at Fletcher's Ice Island ( $T_{-} 3$ ) from $6 / 11 / 61$ to $7 / 7 / 61$ (heavy line). Inverted or water barometer at $\mathrm{T}_{-} 3$ and Point Barrow (light lines). Winds at $\mathrm{I}-3$ and Point Barrow (arrows). Large arrows indicate closest passage to T-3 of two lows.

Figure 5 Surface weather chart for 0800 AST 30 May, 1961, approximately the time of closest passage to T-3 of the high. Pressure in millibars. Dashed line represents track of high. Open circles represent positions of high-pressure center at six-hour intervals. 


\section{LISI OF ILLUSTRATIONS}

Figure 6 Surface weather chart for 0800 AST 18 June, 1961. Pressure in millibars. Dashed line represents storm track. Open circles represent positions of low-pressure system at six-hour intervals.

Figure 7 Surface weather chart for 0800 ASI 6 July, 1961. Dashed line represents storm track. Open circles represent positions of low-pressure system at sixhour intervals.

Figure 8 Storm surge heights for the storm of $6 / 17 / 61$ to $6 / 19 / 61$. Calculated storm surge heights (heavy line) are based on the application of Ekman's theory and Bernoulli's equation to a section through an idealized version of the storm. The section is taken through the storm center along the direction of storm propagation. Wind, ice, and current vectors are shown in plan view along this section. Atmospheric pressure is represented by dashed line. Observed storm surge heights at T-3 for $6 / 17 / 61$ to $6 / 19 / 61$ (light line) are shown for comparison. 


\section{REFERENCES}

Ekman, V. Wo, On the influence of the earth's rotation on ocean currents; Ark. Math. Astr. och Fys. 2, no. 1l, Stockholm, 1905.

Fjeldstad, J. E., Results of tidal observations; in Scientific Results of the Norwegian North Polar Expedition with the MAUD 1918-1925; vol. iv, Bergen, 1936. Harris, D. L., Some problems involved in the study of storm surges; Natl. Hurricane Research Proj., Rept. no. 4, (preprinted) U. S. Dept. of Commerce, Wash., 1956. Harris, R. A., Arctic tides; U. S. Coast and Geodetic Survey, Wash., 1911. Hessen, K., Gezeiten und Strombeobachtungen auf der Winterstation der GAUSS 1902-3; Deutsche Sudpolar Exp. 7, 561, Berlin, 1932. (This reference not seen by author). Hunkins, K., Waves on the Arctic Ocean; J. Geophys. Research, $67,2477-2489,1962$.

Kusunaki, K., J. Muguruma, and K. Higuchi, Oceanographic observations at Fletcher's Ice Island ( $T_{-} 3$ ) in the Arctic Ocean in 1959-1960; Sci. Rept. No. 4, Contract AF19 (604) 8343, AFCRL-62-479, GRD, Air Force Cambridge Research Laboratories, Bedford, Mass., 1962. Marmer, H. A., Arctic tides; in Problems of Polar Research; Am. Geogr, Soc., Spec. Pub. No. 7, New York, 1928. 
Ross, Sir J. C., On the effect of the pressure of the atmosphere on the mean level of the ocean; Phil. Trans. Roy. Soc. London, 144, 285-296, 1854.

Schureman, P., Manual of harmonic analysis and prediction of tides; U. S. Dept. of Commerce, Coast and Geodetic Survey, Spec. Pub. No. 98, Wash., 1958.

Sverdrup, H. U., Dynamic of tides on the North_Siberian shelf;

Geofys. Publikasjoner, 4, no. 5, Oslo, 1926. Sverdrup, H. U., The wind-drift of the ice on the NorthSiberian shelf; in Scientific Results of the Norwegian North Polar Expedition with the MAUD 1918-1925; vol. iv, Bergen, 1936a.

Sverdrup, H. U., The waters on the North-Siberian shelf; in

Scientific Results of the Norwegian North Polar Expedition with the MAUD 1918-1925; vol. iv, Bergen, 1936b. Wegener, A., Luftdruck und Mittelwasser am Danmark-Havn; Ann. Hydr. Mar. Met., p. 22, 1924. - Oceanographic Atlas of the Polar Seas, Part II, Arctic; U. S. Navy Hydrographic Office, Publ. no. 705, 139 pp., 1958. 


\section{APPENDIX}

HOURLY VALUES OF SEA LEVEL HEIGHTS

AI

FLETCHER'S ICE ISLAND (T-3)

MAY 15 to JULY 7, 1961

$71^{\circ} 55^{\prime} \mathrm{N} 160^{\circ} 20 \cdot \mathrm{W}$ 
TIDE OBJERVATIONS - FLETCIER'S ICE ISLAND (T-3)

$71^{\circ} 55^{\prime} \mathrm{N}-160^{\circ} 20^{\prime} \mathrm{W}$

Hourly heights in meters

referred to arbitrary base.

1961

Time meridian : $150^{\circ}$

\begin{tabular}{|c|c|c|c|c|c|c|c|c|}
\hline \multicolumn{9}{|c|}{ ton } \\
\hline Day of Series & 1 & 2 & 3 & 4 & 5 & 6 & 2 & 8 \\
\hline \multicolumn{9}{|l|}{ Eour } \\
\hline 0 & & 1.174 & 1.131 & 1.300 & 1.281 & 1.195 & 1.198 & 1.102 \\
\hline 1 & & 1.173 & 1.170 & 1.322 & 1.305 & 1.214 & 1.205 & 1.106 \\
\hline 2 & & 1.150 & 1.188 & 1.333 & 1.309 & 1.232 & 1.214 & 1.118 \\
\hline 3 & & 1.125 & 1.158 & 1.325 & 1.303 & 1.242 & 1.228 & 1.130 \\
\hline 4 & & 1.097 & 1.125 & 1.300 & 1.287 & 1.237 & 1.232 & 1.135 \\
\hline 5 & & 1.064 & 1.093 & 1.275 & 1.262 & 1.213 & 1.224 & 1.128 \\
\hline 6 & & 1.042 & 1.075 & 1.242 & 1.232 & 1.199 & 1.201 & 1.120 \\
\hline 7 & & 1.034 & 1.067 & 1.226 & 1.208 & 1.177 & 1.177 & 1.104 \\
\hline 8 & & 1.050 & 1.072 & 1.212 & 1.188 & 1.159 & 1.167 & 1.095 \\
\hline 9 & & 1.085 & 1.102 & 1.230 & 1.186 & 1.149 & 1.145 & 1.078 \\
\hline 10 & & 1.125 & 1.140 & 1.252 & 1.195 & 1.154 & 1.139 & 1.069 \\
\hline 11 & & 1.172 & 1.180 & 1.283 & 1.220 & 1.171 & 1.139 & 1.066 \\
\hline 12 & & 1.195 & 1.217 & 1.320 & 1.248 & 1.197 & 1.153 & 1.078 \\
\hline 13 & & 1.202 & 1.242 & 1.347 & 1.268 & 1.217 & 1.173 & 1.092 \\
\hline 14 & & 1.192 & 1.250 & 1.359 & 1.286 & 1.248 & 1.192 & 1.103 \\
\hline 15 & & 1.162 & 1.243 & 1.352 & 1.282 & 1.264 & 1.205 & 1.127 \\
\hline 16 & & 1.117 & 1.315 & 1.345 & 1.272 & 1.268 & 1.203 & 1.135 \\
\hline 17 & 1.097 & 1.090 & 1.275 & 1.317 & 1.252 & 1.264 & 1.197 & 1.149 \\
\hline 18 & 1.070 & 1.050 & 1.243 & 1.289 & 1.227 & 1.244 & 1.183 & 1.154 \\
\hline 19 & 1.057 & 1.038 & 1.219 & 1.259 & 1.194 & 1.222 & 1.166 & 1.148 \\
\hline 20 & 1.065 & 1.037 & 1.212 & 1.235 & 1.170 & 1.194 & 1.144 & 1.128 \\
\hline 21 & 1.082 & 1.060 & 1.222 & 1.234 & 1.164 & 1.180 & 1.128 & 1.113 \\
\hline 22 & 1.117 & 1.071 & 1.235 & 1.243 & 1.162 & 1.173 & 1.108 & 1.109 \\
\hline 23 & 1.150 & 1.095 & 1.265 & 1.257 & 1.180 & 1.184 & 1.100 & 1.108 \\
\hline
\end{tabular}


TIDE OBSERVAIIONS con'd

Page II

Ist Series

\begin{tabular}{|c|c|c|c|c|c|c|c|}
\hline Mo. \& Day & IAY 23 & 24 & 25 & 26 & 27 & 28 & 29 \\
\hline Day of Series & 9 & 10 & 11 & 12 & 13 & 14 & 15 \\
\hline \multicolumn{8}{|l|}{ Hour } \\
\hline 0 & 1.109 & 1.109 & 1.203 & 1.315 & 1.203 & 1.271 & 1.275 \\
\hline 1 & 1.121 & 1.106 & 1.206 & 1.296 & 1.177 & 1.246 & 1.244 \\
\hline 2 & 1.138 & 1.104 & 1.223 & 1.271 & 1.159 & 1.225 & 1.222 \\
\hline 3 & 1.156 & 1.106 & 1.223 & 1.246 & 1.147 & 1.205 & 1.197 \\
\hline 4 & 1.181 & 1.112 & 1.237 & 1.246 & 1.145 & 1.195 & 1.176 \\
\hline 5 & 1.193 & 1.121 & 1.246 & 1.249 & 1.155 & 1.199 & 1.156 \\
\hline 6 & 1.200 & 1.132 & 1.292 & 1.274 & 1.179 & 1.212 & 1.149 \\
\hline 7 & 1.196 & 1.138 & 1.324 & 1.294 & 1.210 & 1.239 & 1.158 \\
\hline 8 & 1.191 & 1.141 & 1.348 & 1.296 & 1.239 & 1.278 & 1.201 \\
\hline 9 & 1.181 & 1.143 & 1.391 & 1.311 & 1.275 & 1.322 & 1.236 \\
\hline 10 & 1.173 & 1.144 & 1.384 & 1.312 & 1.281 & 1.345 & 1.259 \\
\hline 11 & 1.170 & 1.130 & 1.368 & 1.295 & 1.277 & 1.355 & 1.266 \\
\hline 12 & 1.170 & 1.121 & 1.351 & 1.272 & 1.272 & 1.347 & 1.272 \\
\hline 13 & 1.171 & 1.126 & 1.341 & 1.244 & 1.258 & 1.325 & 1.257 \\
\hline 14 & 1.171 & 1.136 & 1.332 & 1.221 & 1.232 & 1.297 & 1.225 \\
\hline 15 & 1.171 & 1.144 & 1.323 & 1.198 & 1.215 & 1.255 & 1.177 \\
\hline 16 & 1.175 & 1.161 & 1.326 & 1.183 & 1.205 & 1.232 & 1.137 \\
\hline 17 & 1.185 & 1.186 & 1.341 & 1.184 & 1.200 & 1.221 & 1.112 \\
\hline 18 & 1.189 & 1.190 & 1.346 & 1.191 & 1.205 & 1.224 & 1.105 \\
\hline 19 & 1.176 & 1.194 & 1.351 & 1.199 & 1.224 & 1.236 & 1.111 \\
\hline 20 & 1.169 & 1.211 & 1.356 & 1.210 & 1.242 & 1.251 & 1.135 \\
\hline 21 & 1.150 & 1.206 & 1.356 & 1.219 & 1.267 & 1.272 & 1.159 \\
\hline 22 & 1.138 & 1.201 & 1.349 & 1.223 & 1.276 & 1.291 & 1.181 \\
\hline 23 & 1.120 & 1.201 & 1.332 & 1.219 & 1.275 & 1.295 & 1.197 \\
\hline
\end{tabular}


TIDE OBSERVATIUNS cont'd

Page III

lst Series

\begin{tabular}{cccccccc} 
Mo. \& Day & MAY 30 & 31 & JUN 1 & 2 & 3 & 4 & 5 \\
\hline Day of Series & 16 & 17 & 18 & 19 & 20 & 21 & 22 \\
\hline Hour & & & & & & & \\
0 & 1.201 & 1.281 & 1.416 & 1.398 & 1.263 & 1.137 & 1.092 \\
1 & 1.185 & 1.289 & $(1.435)$ & 1.408 & 1.274 & 1.161 & 1.114 \\
2 & 1.147 & 1.269 & $(1.432)$ & 1.410 & 1.280 & 1.174 & 1.138 \\
3 & 1.122 & 1.241 & $(1.415)$ & 1.384 & 1.277 & 1.183 & 1.151 \\
4 & 1.100 & 1.210 & 1.386 & 1.354 & 1.252 & 1.182 & 1.137 \\
5 & $(1.089)$ & 1.182 & 1.365 & 1.324 & 1.218 & 1.167 & 1.166 \\
6 & $(1.089)$ & $(1.176)$ & 1.341 & 1.276 & 1.192 & 1.139 & 1.158 \\
7 & $(1.097)$ & $(1.184)$ & 1.324 & 1.252 & 1.172 & 1.116 & 1.138 \\
8 & 1.134 & 1.208 & 1.351 & 1.233 & 1.148 & 1.086 & 1.116 \\
9. & 1.180 & 1.263 & 1.387 & 1.247 & 1.142 & 1.071 & 1.101 \\
10 & 1.215 & 1.315 & 1.422 & 1.268 & 1.148 & 1.079 & 1.093 \\
11 & 1.242 & 1.355 & 1.452 & 1.303 & 1.172 & 1.100 & 1.093 \\
12 & 1.264 & 1.388 & 1.486 & 1.335 & 1.200 & 1.118 & 1.111 \\
13 & 1.261 & 1.406 & 1.505 & 1.363 & 1.222 & 1.143 & 1.141 \\
14 & 1.248 & 1.396 & 1.513 & 1.368 & 1.228 & 1.160 & 1.157 \\
15 & 1.221 & 1.376 & 1.492 & 1.359 & 1.226 & 1.168 & 1.178 \\
16 & 1.189 & 1.360 & $(1.457)$ & 1.338 & 1.221 & 1.172 & 1.196 \\
17 & 1.164 & 1.321 & $(1.427)$ & 1.297 & 1.193 & 1.170 & 1.201 \\
18 & 1.147 & 1.301 & $(1.398)$ & 1.264 & 1.170 & 1.146 & 1.201 \\
19 & 1.143 & 1.287 & $(1.367)$ & 1.230 & 1.129 & 1.115 & 1.186 \\
20 & 1.162 & 1.298 & $(1.346)$ & 1.219 & 1.107 & 1.095 & 1.172 \\
21 & 1.189 & 1.326 & 1.338 & 1.217 & 1.101 & 1.076 & 1.160 \\
22 & 1.223 & 1.355 & 1.357 & 1.225 & 1.104 & 1.071 & 1.146 \\
23 & 1.252 & 1.382 & 1.381 & 1.243 & 1.119 & 1.075 & 1.134
\end{tabular}

Parentheses indicate interpolated values 
TIDE OBSERVATIONS cont'd

Page IV

lst Series

\begin{tabular}{ccc} 
Mo. \& Day & JUN 6 & 7 \\
\hline Day of series & 23 & 24 \\
\hline Hour & & \\
0 & 1.138 & 1.229 \\
1 & 1.153 & 1.241 \\
2 & 1.176 & 1.260 \\
3 & 1.202 & 1.280 \\
4 & 1.226 & 1.302 \\
5 & 1.231 & 1.326 \\
6 & 1.243 & 1.346 \\
7 & 1.240 & 1.364 \\
8 & 1.235 & 1.386 \\
9 & 1.221 & \\
10 & 1.206 & \\
11 & 1.202 & \\
12 & 1.206 & \\
13 & 1.216 & \\
14 & 1.228 & \\
15 & 1.243 & \\
16 & 1.253 & \\
17 & 1.269 & \\
18 & 1.279 & \\
19 & 1.269 & \\
20 & 1.261 & \\
21 & 1.256 & \\
22 & 1.237 &
\end{tabular}




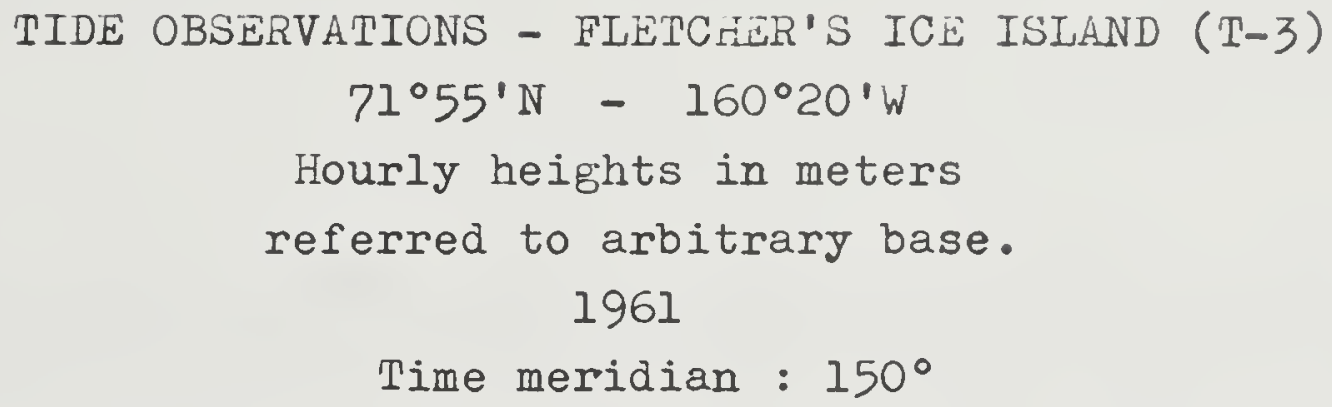

2nd Series

\begin{tabular}{|c|c|c|c|c|c|c|c|}
\hline Mo. \& Day & JUN 11 & 12 & 13 & 14 & 15 & 16 & 17 \\
\hline Day of Series & 1 & 2 & 3 & 4 & 5 & 6 & 7 \\
\hline \multicolumn{8}{|l|}{ Hour } \\
\hline 0 & & 1.158 & 1.194 & 1.219 & 1.149 & 1.106 & 1.091 \\
\hline 1 & & 1.136 & 1.181 & 1.215 & 1.149 & 1.114 & 1.112 \\
\hline 2 & & 1.105 & 1.161 & 1.200 & 1.130 & 1.115 & 1.122 \\
\hline 3 & & 1.081 & 1.141 & 1.169 & 1.102 & 1.088 & 1.117 \\
\hline 4 & & 1.067 & 1.116 & 1.141 & 1.068 & 1.064 & 1.102 \\
\hline 5 & & 1.057 & 1.097 & 1.111 & 1.038 & 1.032 & 1.082 \\
\hline 6 & & 1.062 & 1.091 & 1.089 & 1.018 & 1.006 & 1.044 \\
\hline 7 & & 1.081 & 1.102 & 1.076 & 1.002 & 0.996 & 1.029 \\
\hline 8 & & 1.117 & 1.125 & 1.090 & 1.012 & 0.981 & 1.032 \\
\hline 9 & 1.161 & 1.159 & 1.168 & 1.143 & 1.049 & 1.013 & 1.048 \\
\hline 10 & 1.173 & 1.200 & 1.207 & 1.173 & 1.089 & 1.047 & 1.066 \\
\hline 11 & 1.184 & 1.213 & 1.243 & 1.199 & 1.127 & 1.083 & 1.087 \\
\hline 12 & 1.175 & 1.212 & 1.255 & 1.228 & 1.138 & 1.113 & 1.134 \\
\hline 13 & 1.160 & 1.188 & 1.247 & 1.225 & 1.155 & 1.136 & 1.156 \\
\hline 14 & 1.142 & 1.174 & 1.220 & 1.203 & 1.148 & 1.134 & 1.182 \\
\hline 15 & 1.106 & 1.146 & 1.194 & 1.170 & 1.129 & 1.115 & 1.199 \\
\hline 16 & 1.076 & 1.126 & 1.164 & 1.137 & 1.098 & 1.098 & 1.214 \\
\hline 17 & 1.066 & 1.093 & 1.130 & 1.096 & 1.067 & 1.078 & 1.198 \\
\hline 18 & 1.063 & 1.068 & 1.107 & 1.064 & 1.031 & 1.042 & 1.200 \\
\hline 19 & 1.071 & 1.088 & 1.098 & 1.058 & 1.024 & 1.011 & 1.208 \\
\hline 20 & 1.096 & 1.109 & 1.126 & 1.065 & 1.023 & 1.003 & 1.211 \\
\hline 21 & 1.120 & 1.147 & 1.162 & 1.086 & 1.038 & 1.015 & 1.225 \\
\hline 22 & 1.145 & 1.170 & 1.191 & 1.113 & 1.062 & 1.032 & 1.218 \\
\hline 23 & 1.159 & 1.188 & 1.207 & 1.138 & 1.093 & 1.054 & 1.233 \\
\hline
\end{tabular}


TIDE OBSERVATIONS cont'd

Page II

2nd Series

\begin{tabular}{cccccccc} 
Mo. \& DaJ & JN 18 & 19 & 20 & 21 & 22 & 23 & 24 \\
\hline DaI of Series & 8 & 9 & 10 & 11 & 12 & 13 & 14 \\
\hline Hour & & & & & & & \\
0 & 1.268 & 1.034 & 1.023 & $(1.146)$ & 1.158 & 1.175 & 1.110 \\
1 & 1.289 & 1.044 & 1.047 & $(1.160)$ & 1.168 & 1.173 & 1.113 \\
2 & 1.308 & 1.061 & 1.064 & $(1.175)$ & 1.188 & 1.179 & 1.121 \\
3 & 1.315 & 1.077 & 1.089 & $(1.193)$ & 1.213 & 1.195 & 1.146 \\
4 & 1.326 & 1.083 & 1.102 & $(1.208)$ & 1.233 & 1.216 & 1.170 \\
5 & 1.326 & 1.064 & 1.107 & $(1.216)$ & 1.245 & 1.250 & 1.194 \\
6 & 1.318 & 1.028 & 1.103 & $(1.214)$ & 1.250 & 1.245 & 1.207 \\
7 & 1.302 & 1.011 & 1.094 & $(1.201)$ & 1.256 & 1.243 & 1.224 \\
8 & 1.275 & 0.991 & 1.075 & $(1.180)$ & 1.247 & 1.242 & 1.228 \\
9 & 1.252 & 0.978 & 1.064 & 1.164 & 1.234 & 1.233 & 1.232 \\
10 & 1.191 & 0.960 & 1.067 & 1.159 & 1.223 & 1.223 & 1.227 \\
11 & 1.178 & 0.981 & 1.074 & 1.168 & 1.206 & 1.212 & 1.221 \\
12 & $(1.226)$ & 0.991 & 1.105 & 1.176 & 1.204 & 1.203 & 1.210 \\
13 & 1.229 & 1.019 & 1.142 & 1.188 & 1.206 & 1.197 & 1.206 \\
14 & 1.230 & 1.056 & 1.160 & 1.202 & 1.217 & 1.191 & 1.188 \\
15 & 1.237 & 1.061 & 1.170 & 1.215 & 1.232 & 1.185 & 1.175 \\
16 & 1.212 & 1.059 & 1.192 & 1.224 & 1.243 & 1.181 & 1.176 \\
17 & 1.183 & 1.048 & 1.190 & 1.228 & 1.251 & 1.184 & 1.179 \\
18 & 1.158 & 1.044 & 1.175 & 1.213 & 1.253 & 1.187 & 1.188 \\
19 & 1.106 & 1.030 & $(1.160)$ & 1.196 & 1.244 & 1.186 & 1.188 \\
20 & 1.057 & 0.988 & $(1.145)$ & 1.184 & 1.234 & 1.184 & 1.186 \\
21 & 1.041 & 0.976 & $(1.132)$ & 1.165 & 1.224 & 1.170 & 1.189 \\
22 & 1.046 & 0.988 & $(1.128)$ & 1.149 & 1.202 & 1.155 & 1.182 \\
23 & 1.034 & 0.996 & $(1.135)$ & 1.151 & 1.192 & 1.132 & 1.174
\end{tabular}

Parentheses indicate interpolated values 
TIDE OBSERVATIONS cont'd

Page III

2nd Series

\begin{tabular}{cccccccc} 
Mo. \& Day & JUN 25 & 26 & 27 & 28 & 29 & 30 & JULY 1 \\
Day of Series & 15 & 16 & 17 & 18 & 19 & 20 & 21 \\
\hline Hour & & & & & & & \\
0 & 1.163 & 1.159 & 1.065 & 1.136 & 1.155 & 1.206 & 1.189 \\
1 & 1.138 & 1.142 & 1.033 & 1.115 & 1.149 & 1.198 & 1.195 \\
2 & 1.135 & 1.125 & $(1.018)$ & 1.084 & $(1.133)$ & 1.190 & 1.189 \\
3 & 1.133 & 1.110 & $(1.007)$ & 1.066 & $(1.107)$ & 1.181 & 1.167 \\
4 & 1.139 & 1.108 & $(1.002)$ & 1.036 & $(1.082)$ & 1.154 & 1.155 \\
5 & 1.169 & 1.113 & $(1.002)$ & 1.024 & $(1.056)$ & 1.121 & 1.138 \\
6 & 1.185 & 1.133 & $(1.013)$ & 1.027 & $(1.046)$ & 1.096 & 1.106 \\
7 & 1.202 & 1.157 & $(1.035)$ & 1.046 & 1.045 & 1.091 & 1.082 \\
8 & 1.234 & 1.180 & $(1.080)$ & 1.084 & 1.066 & 1.106 & 1.087 \\
9 & 1.244 & 1.203 & 1.098 & 1.136 & 1.118 & 1.138 & 1.117 \\
10 & 1.252 & 1.217 & 1.129 & 1.174 & 1.152 & 1.174 & 1.143 \\
11 & 1.242 & 1.218 & 1.145 & 1.189 & 1.189 & 1.203 & 1.193 \\
12 & 1.223 & 1.197 & 1.139 & 1.196 & 1.213 & 1.235 & 1.233 \\
13 & 1.203 & 1.160 & 1.118 & 1.188 & 1.215 & 1.252 & 1.263 \\
14 & 1.175 & 1.129 & 1.102 & 1.168 & 1.208 & 1.249 & 1.276 \\
15 & 1.143 & 1.099 & 1.076 & 1.138 & 1.181 & 1.225 & 1.277 \\
16 & 1.148 & 1.071 & 1.055 & 1.102 & 1.155 & 1.197 & 1.262 \\
17 & 1.148 & 1.060 & 1.037 & 1.088 & 1.124 & 1.166 & 1.246 \\
18 & 1.154 & 1.059 & 1.033 & 1.071 & 1.107 & 1.134 & 1.234 \\
19 & 1.174 & 1.067 & 1.044 & 1.055 & 1.096 & 1.110 & 1.215 \\
20 & 1.186 & 1.086 & 1.065 & 1.086 & 1.109 & 1.103 & 1.210 \\
21 & 1.191 & 1.098 & 1.039 & 1.111 & 1.141 & 1.115 & 1.214 \\
22 & 1.189 & 1.093 & 1.107 & 1.135 & 1.167 & 1.144 & 1.234 \\
23 & 1.175 & 1.084 & 1.126 & 1.153 & 1.189 & 1.171 & 1.251
\end{tabular}

Parentheses Indicate Interpolated Values 
TIDE OBSERVATIONS cont'd

Page IV

2nd Series

\begin{tabular}{cccccccc} 
MiO. \& Day & JULY 2 & 3 & 4 & 5 & 6 & 2 & 8 \\
Day of Series & 22 & 23 & 24 & 25 & 26 & 27 & 28 \\
\hline Hour & & & & & & & \\
0 & 1.299 & 1.229 & 1.207 & 1.152 & 1.199 & 1.176 & 1.155 \\
1 & 1.320 & 1.248 & 1.234 & 1.175 & 1.215 & 1.163 & 1.153 \\
2 & 1.329 & 1.255 & 1.254 & 1.197 & 1.260 & 1.151 & 1.157 \\
3 & 1.330 & 1.251 & 1.262 & 1.202 & 1.260 & 1.161 & 1.174 \\
4 & 1.319 & 1.235 & 1.259 & 1.202 & 1.238 & 1.177 & 1.199 \\
5 & 1.302 & 1.219 & 1.246 & 1.200 & 1.303 & 1.188 & 1.241 \\
6 & 1.270 & 1.203 & 1.222 & 1.189 & 1.249 & 1.197 & 1.264 \\
7 & 1.248 & 1.178 & 1.207 & 1.179 & 1.222 & 1.188 & 1.284 \\
8 & 1.233 & 1.164 & 1.185 & 1.166 & 1.205 & 1.182 & 1.296 \\
9 & 1.239 & $(1.155)$ & 1.167 & 1.144 & $(1.196)$ & 1.175 & 1.329 \\
10 & 1.256 & $(1.157)$ & 1.163 & 1.134 & $(1.186)$ & 1.172 & 1.328 \\
11 & 1.288 & $(1.178)$ & 1.171 & 1.146 & $(1.177)$ & 1.169 & 1.326 \\
12 & 1.311 & 1.214 & 1.189 & 1.157 & $(1.166)$ & 1.168 & 1.327 \\
13 & 1.324 & 1.239 & 1.203 & 1.149 & $(1.160)$ & 1.169 & 1.328 \\
14 & 1.333 & 1.256 & 1.209 & 1.177 & $(1.185)$ & 1.170 & 1.326 \\
15 & 1.329 & 1.259 & 1.209 & 1.198 & $(1.229)$ & 1.172 & 1.333 \\
16 & 1.314 & 1.257 & 1.210 & 1.210 & 1.227 & 1.175 & 1.344 \\
17 & 1.223 & 1.244 & 1.203 & 1.211 & 1.210 & 1.171 & 1.350 \\
18 & 1.250 & 1.219 & 1.178 & 1.208 & 1.206 & 1.174 & 1.357 \\
19 & 1.229 & 1.192 & 1.161 & 1.186 & 1.206 & 1.181 & 1.360 \\
20 & 1.204 & 1.172 & 1.143 & 1.182 & 1.214 & 1.177 & 1.364 \\
21 & 1.192 & 1.167 & 1.128 & 1.188 & 1.219 & 1.175 & 1.363 \\
22 & 1.199 & 1.178 & 1.114 & 1.193 & 1.206 & 1.175 & 1.353 \\
23 & 1.210 & 1.188 & 1.129 & 1.187 & 1.191 & 1.160 & 1.341
\end{tabular}

Parentheses Indicate Interpolated Values 
TIDE OBSERVATIONS cont'd

Page $\mathrm{V}$

2nd Series

\begin{tabular}{cccccc} 
Mo. \& DaY & JULY 9 & 10 & 11 & 12 & 13 \\
\hline Day of Series & 29 & 30 & 31 & 32 & 33 \\
\hline Hour & & & & & \\
0 & 1.323 & 1.316 & 1.373 & 1.380 & 1.401 \\
1 & 1.309 & $(1.297)$ & 1.352 & $(1.364)$ & 1.378 \\
2 & $(1.302)$ & $(1.287)$ & $(1.325)$ & 1.334 & 1.338 \\
3 & $(1.303)$ & $(1.285)$ & 1.307 & 1.308 & \\
4 & 1.314 & $(1.289)$ & 1.305 & 1.289 & \\
5 & 1.324 & $(1.297)$ & $(1.311)$ & 1.284 & \\
6 & 1.348 & 1.313 & $(1.322)$ & 1.288 & \\
7 & 1.368 & 1.337 & 1.343 & 1.306 & \\
8 & 1.385 & 1.356 & 1.380 & 1.340 & \\
9 & 1.364 & 1.380 & 1.409 & 1.386 & \\
10 & 1.363 & 1.385 & 1.417 & $(1.402)$ & \\
11 & 1.360 & 1.377 & 1.417 & $(1.407)$ & \\
12 & 1.350 & 1.371 & 1.418 & $(1.407)$ & \\
13 & 1.336 & 1.361 & 1.409 & $(1.402)$ & \\
14 & 1.319 & 1.339 & $(1.356)$ & $(1.392)$ & \\
15 & 1.308 & 1.326 & $(1.329)$ & 1.371 & \\
16 & 1.308 & 1.316 & $(1.313)$ & 1.347 & \\
17 & 1.316 & 1.316 & $(1.309)$ & $(1.333)$ & \\
18 & 1.329 & 1.328 & $(1.313)$ & 1.339 & \\
19 & 1.343 & 1.345 & $(1.323)$ & 1.348 & \\
20 & 1.351 & 1.365 & $(1.341)$ & 1.362 & \\
21 & 1.358 & 1.389 & 1.362 & 1.384 & \\
22 & 1.359 & 1.389 & 1.378 & 1.399 & \\
23 & 1.343 & 1.382 & 1.382 & 1.403 & \\
& & & & &
\end{tabular}

Parentheses Indicate Interpolated Values 


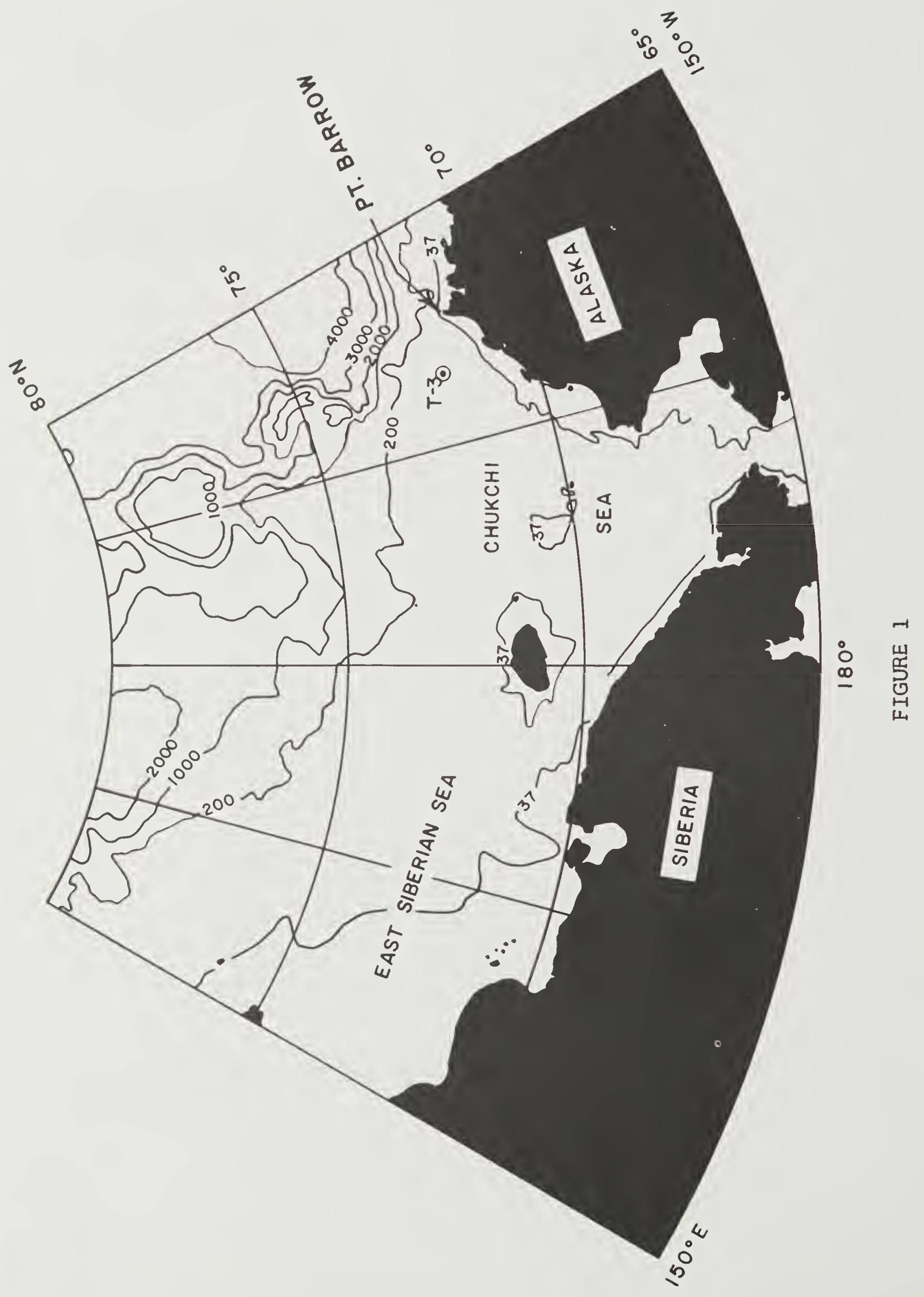




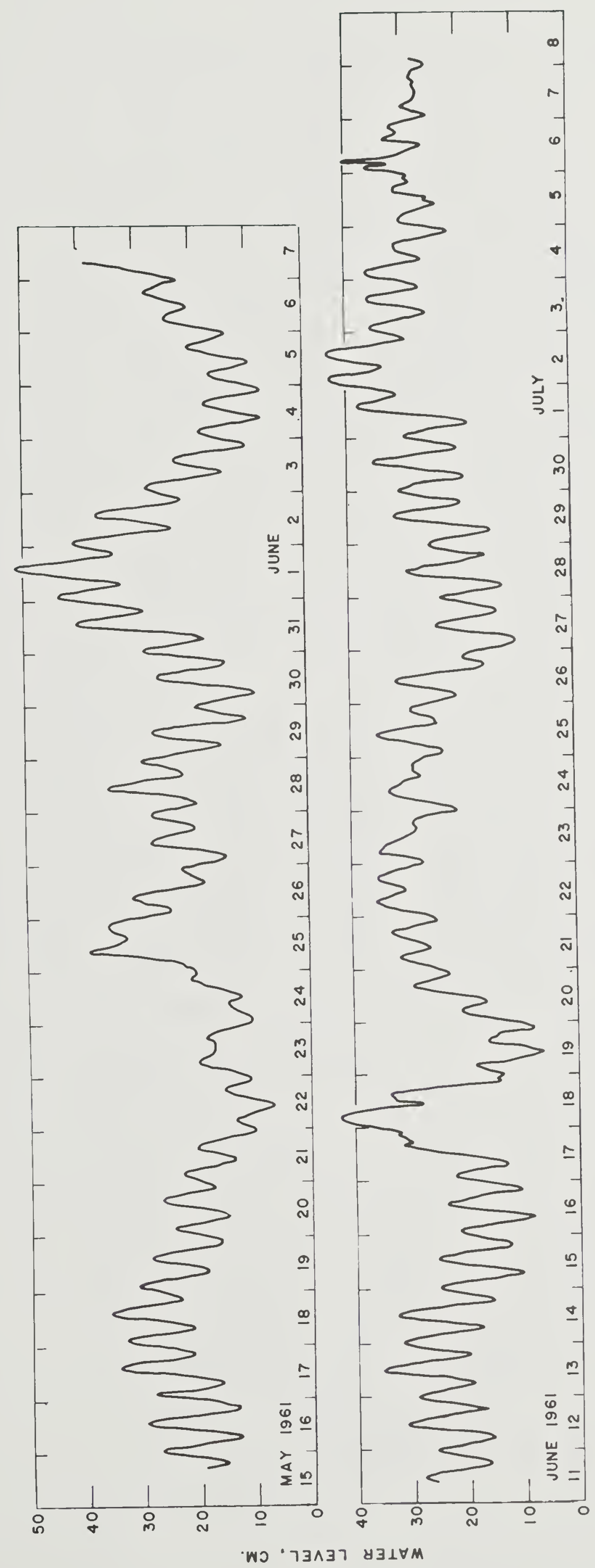

N 


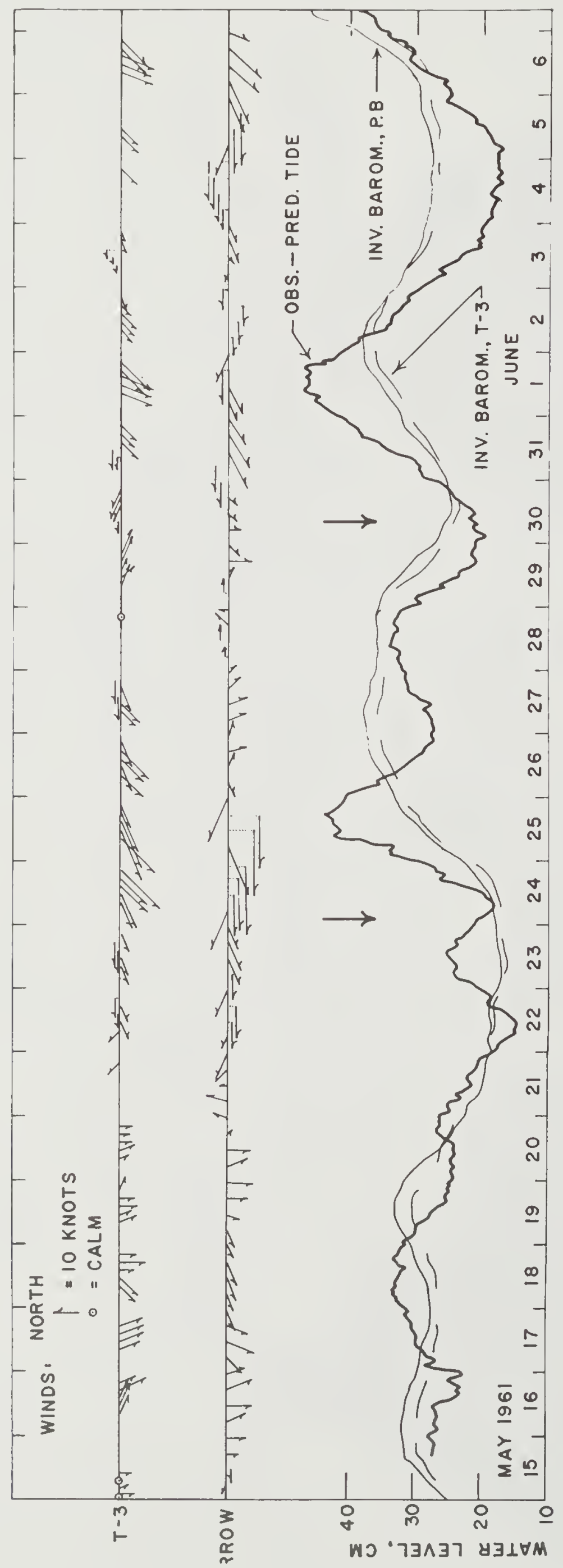

m 


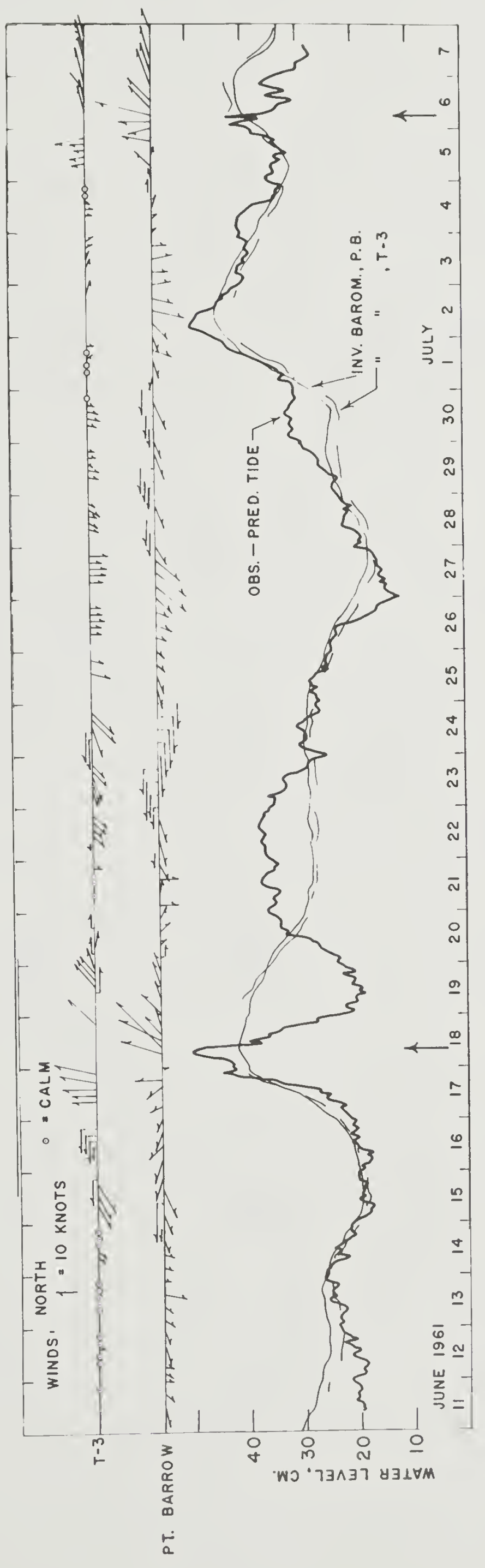

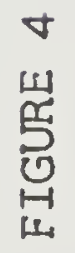




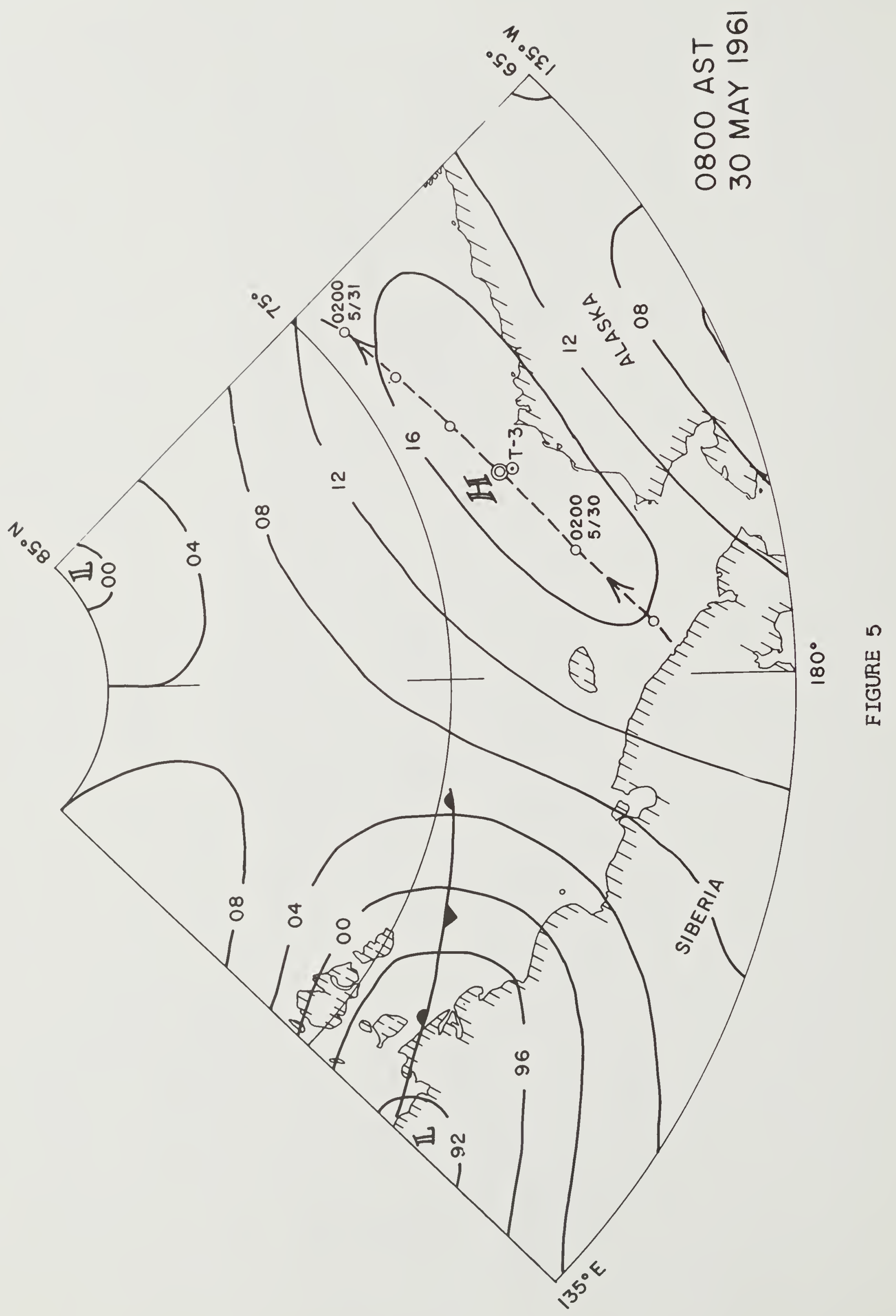




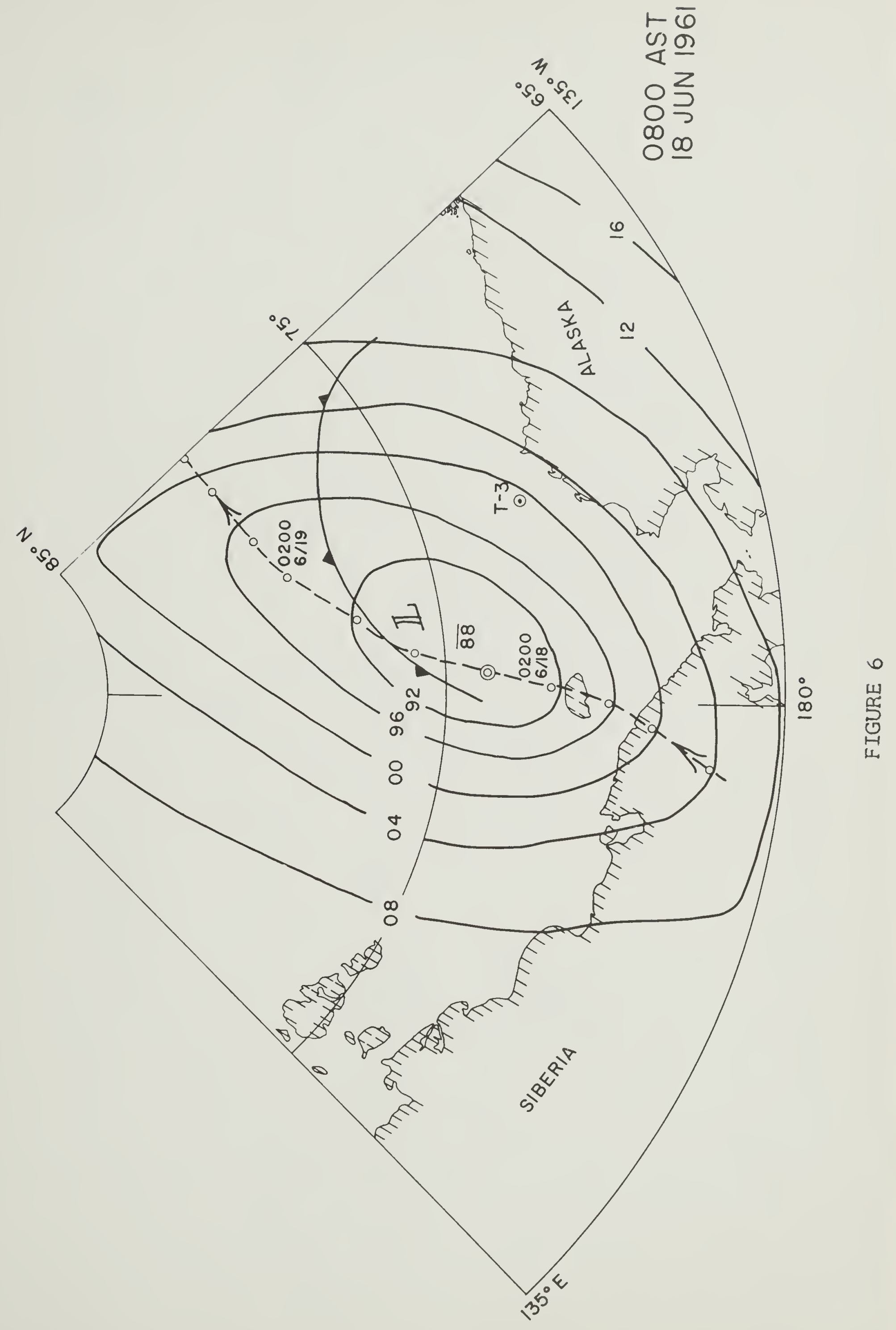




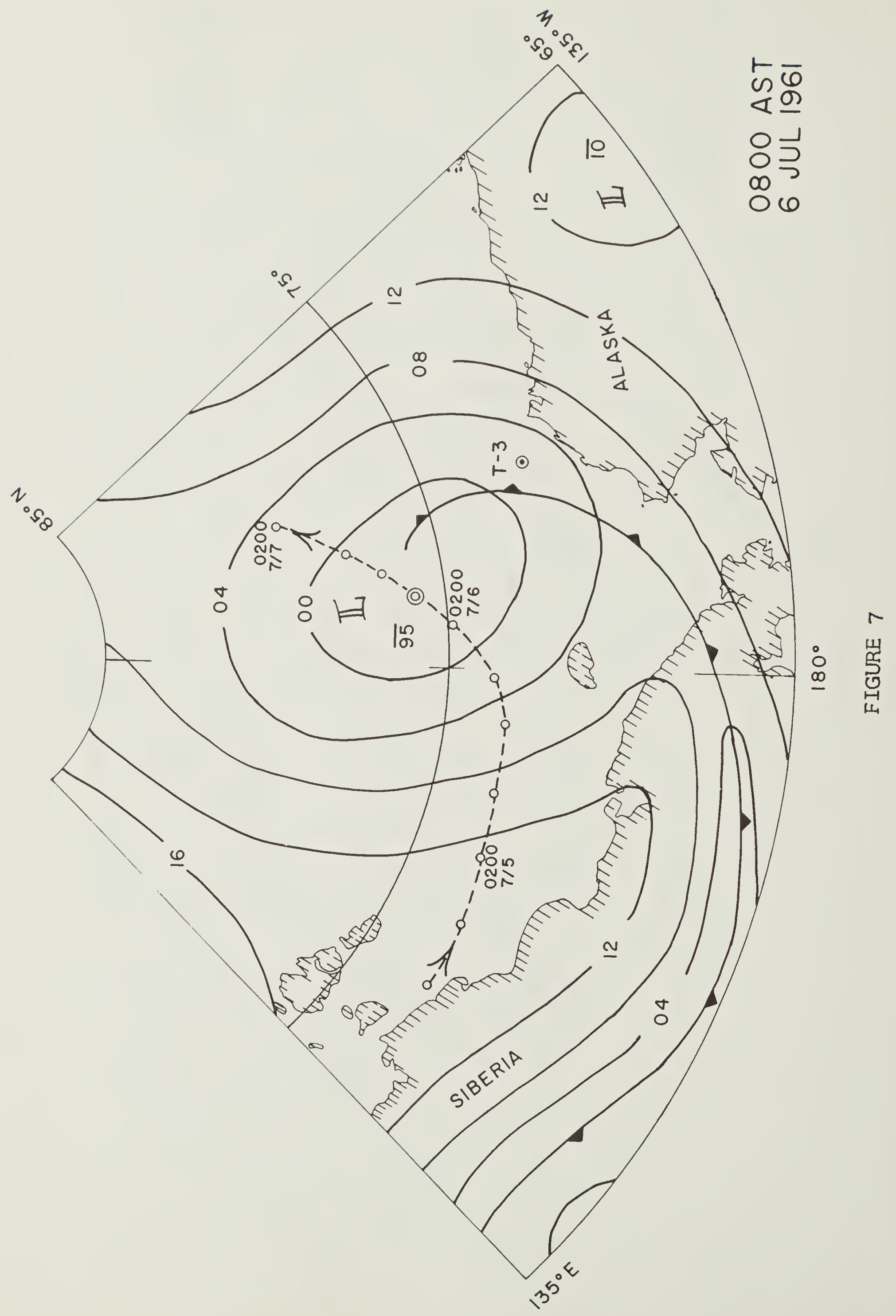




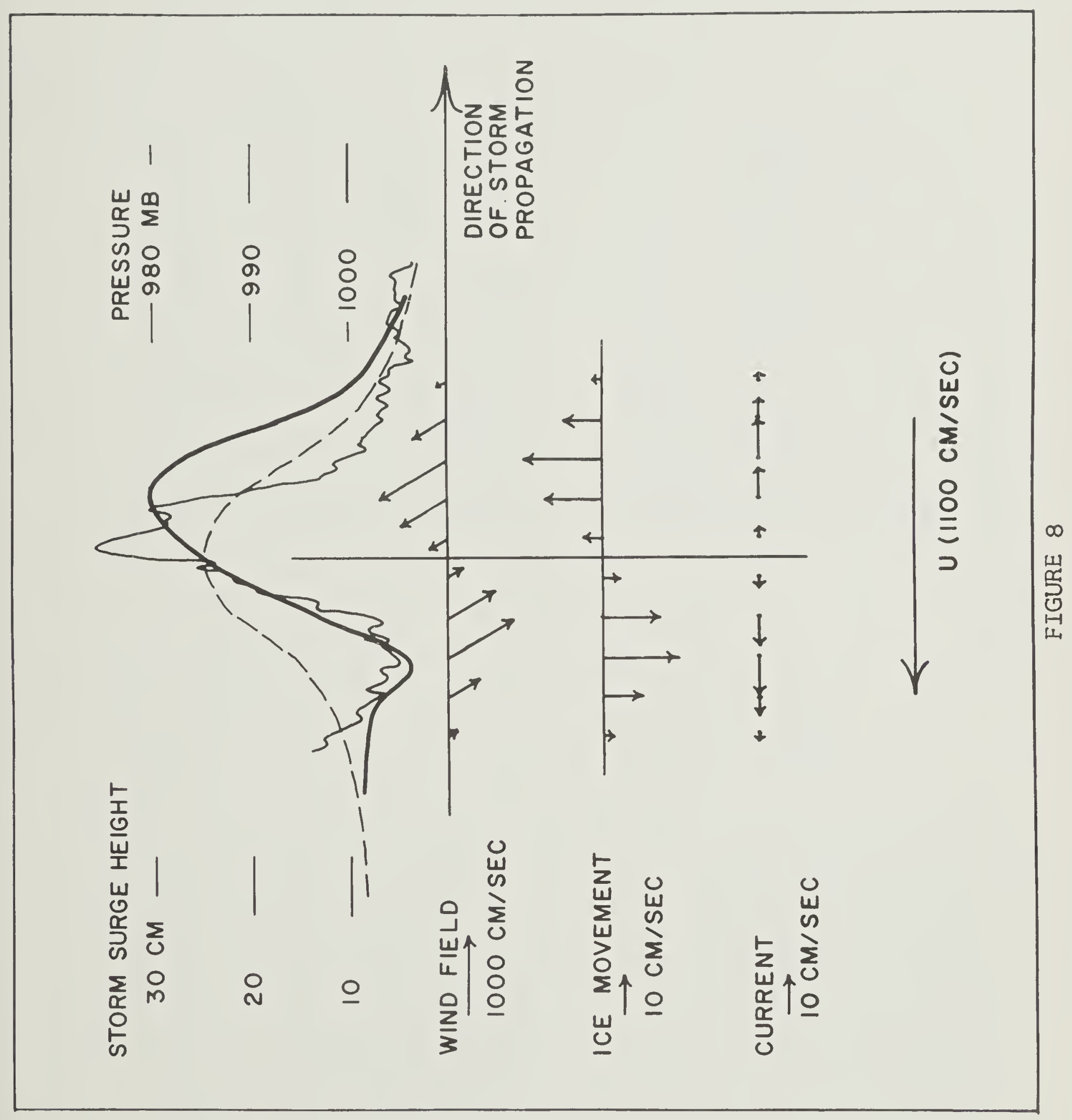




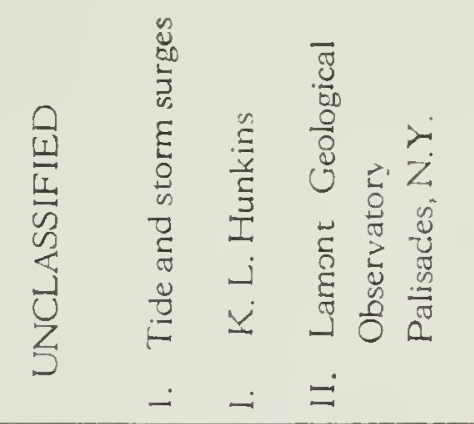

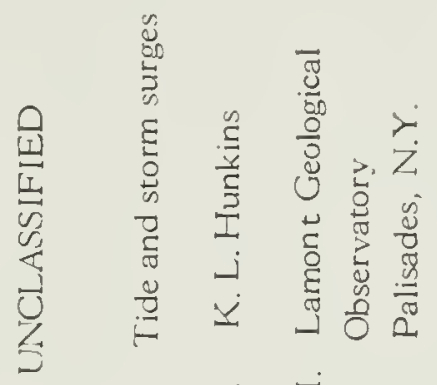

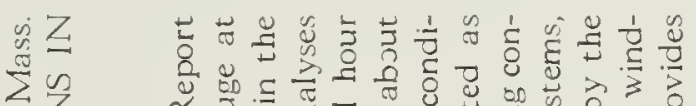

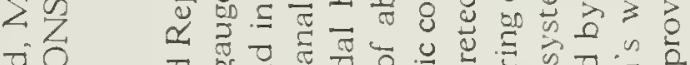

ग0 च

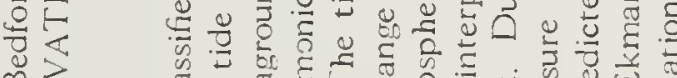

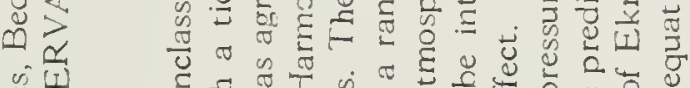

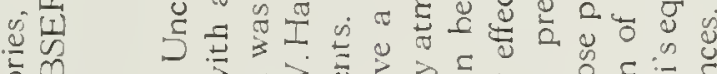

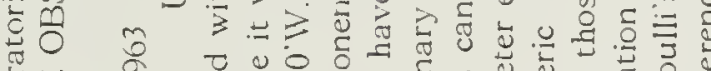

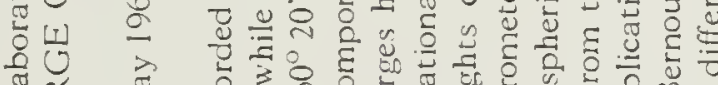

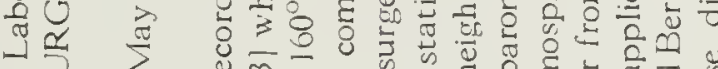

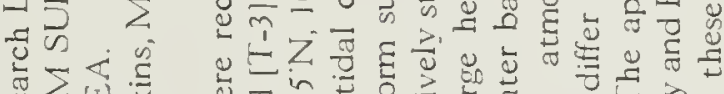

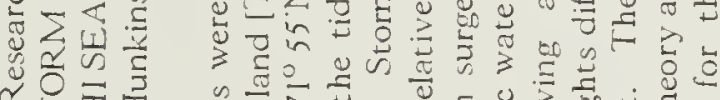

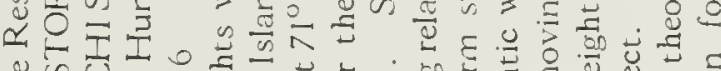

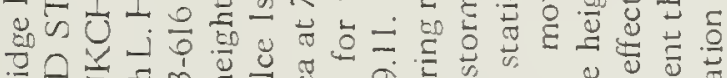

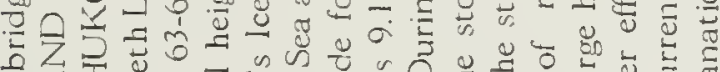

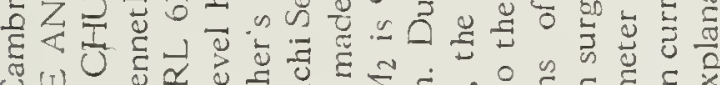

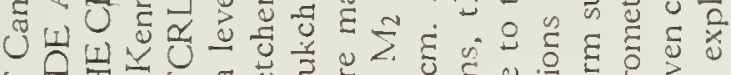

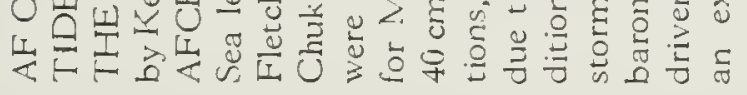

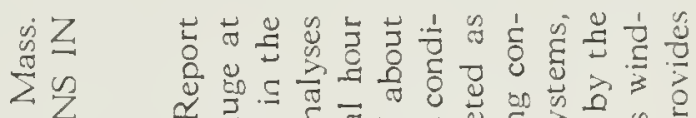

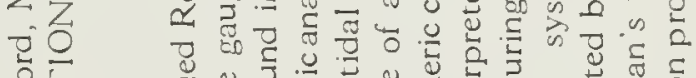

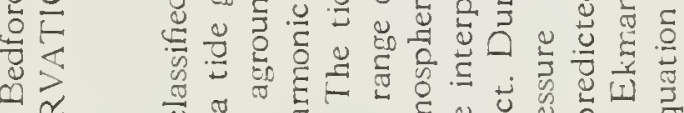

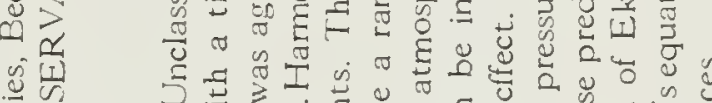

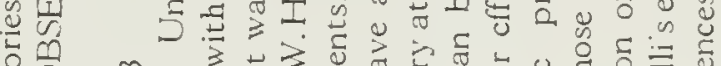

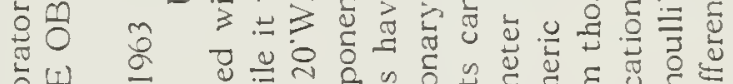

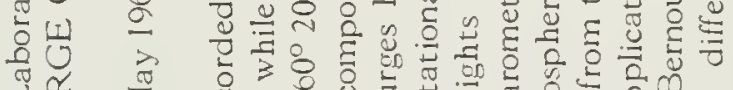

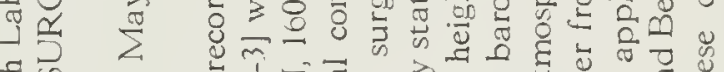

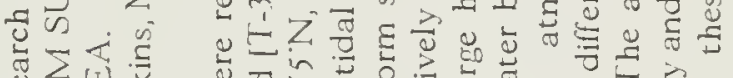

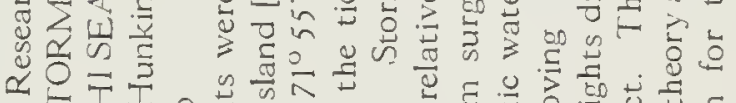

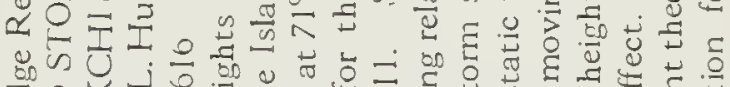

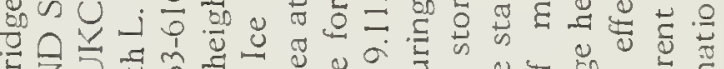

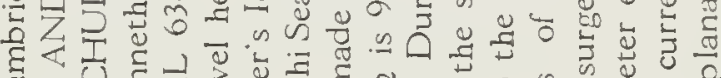

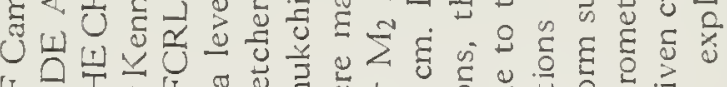

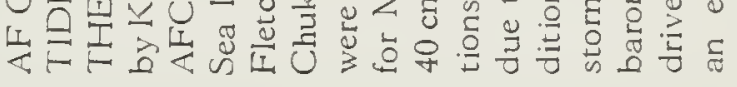

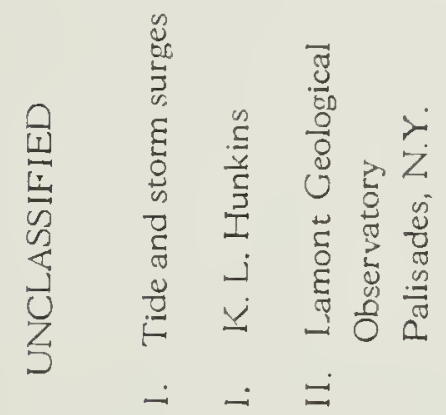

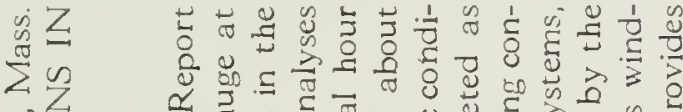

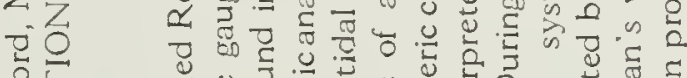

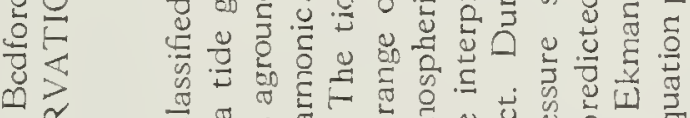

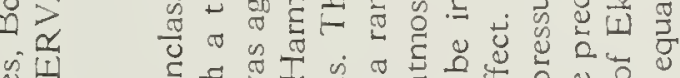

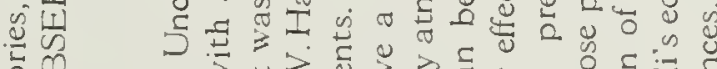

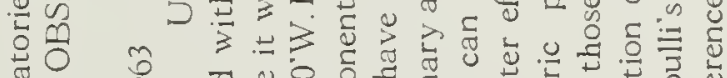

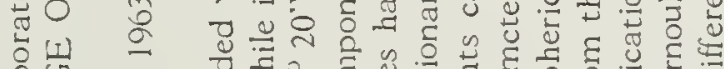

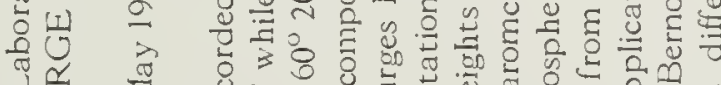

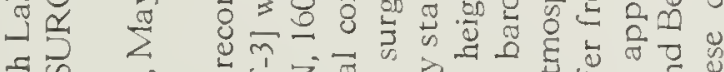
돈,

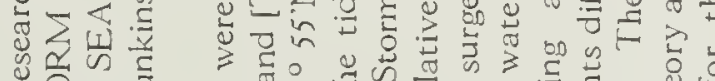

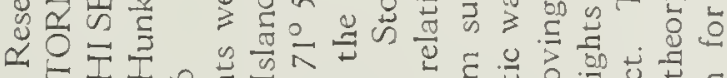

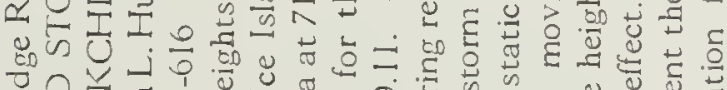

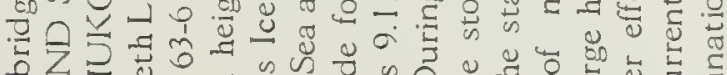
ह

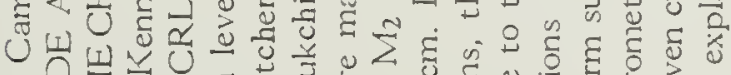

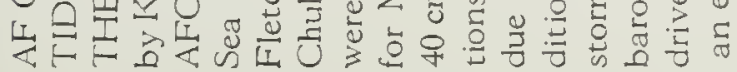

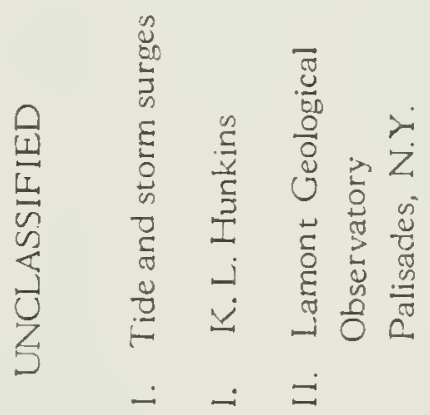

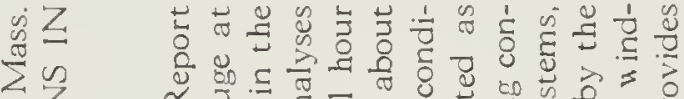

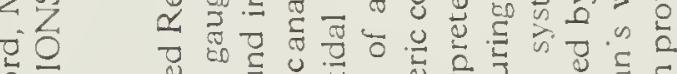

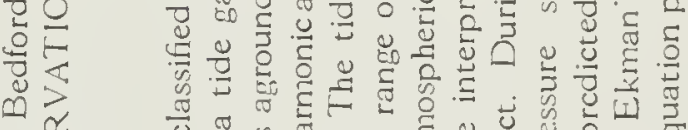
乡山

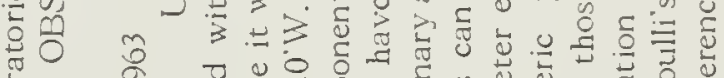
ए山ل

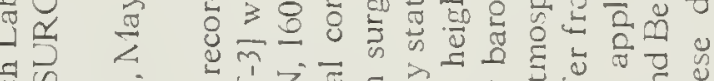
ơ

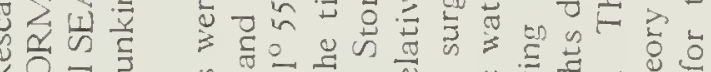

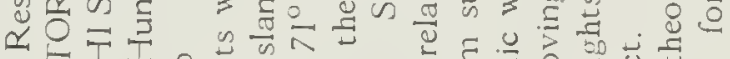

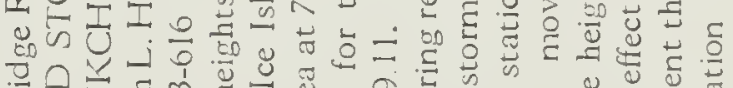

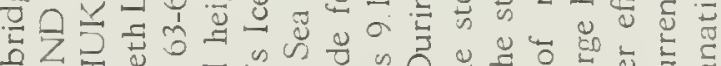

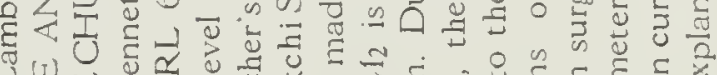

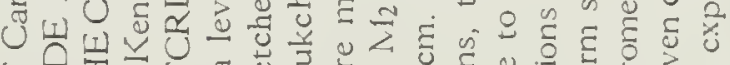

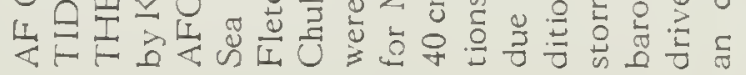



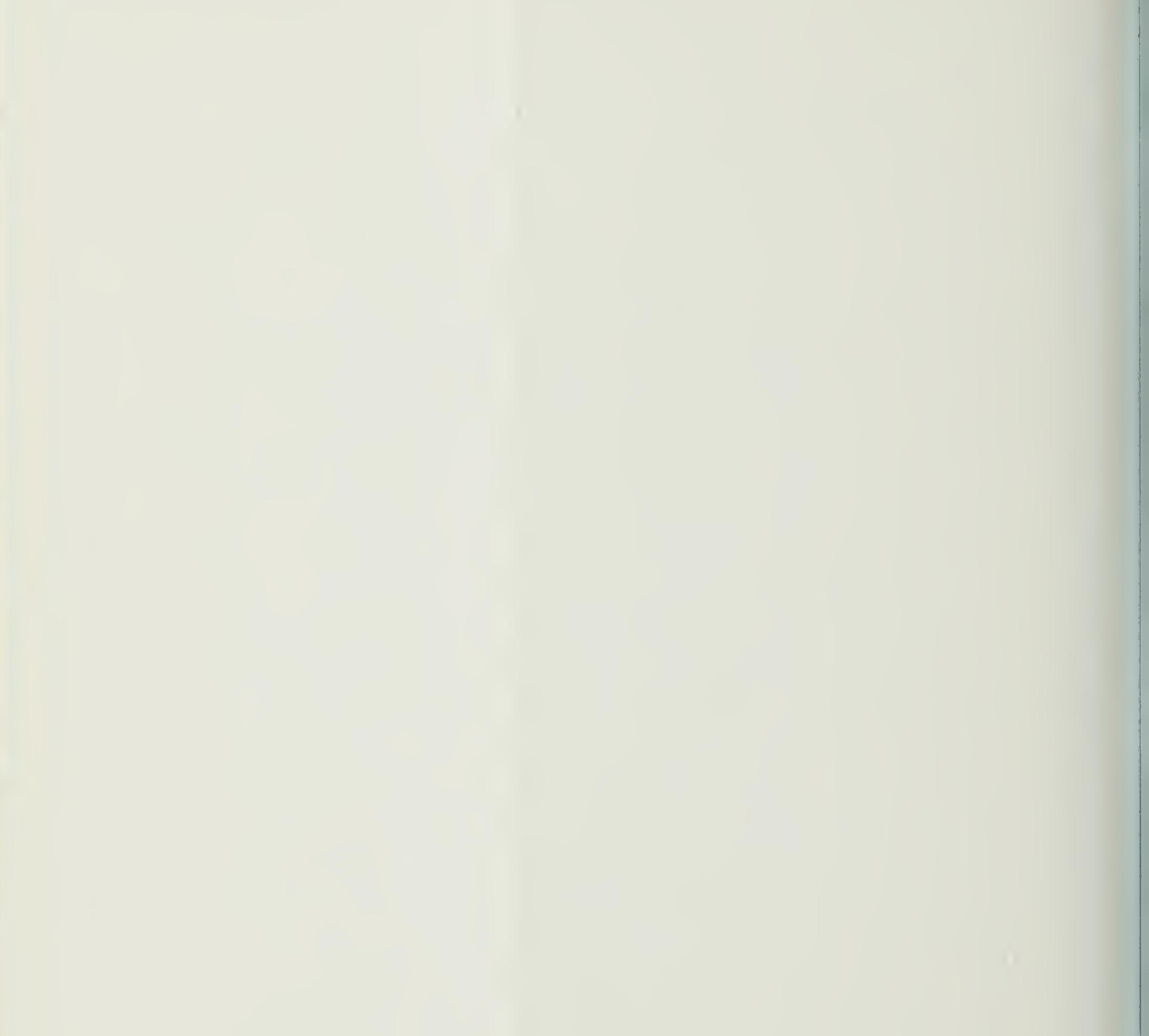
COLUMBIA LIBRARIES OFFSITE

CU90642104 


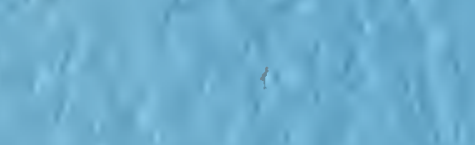

$$
\operatorname{tos}^{2} \sin ^{2}+x^{2}
$$

$1, \div, 1)$

$n^{2}+120 y$

1.
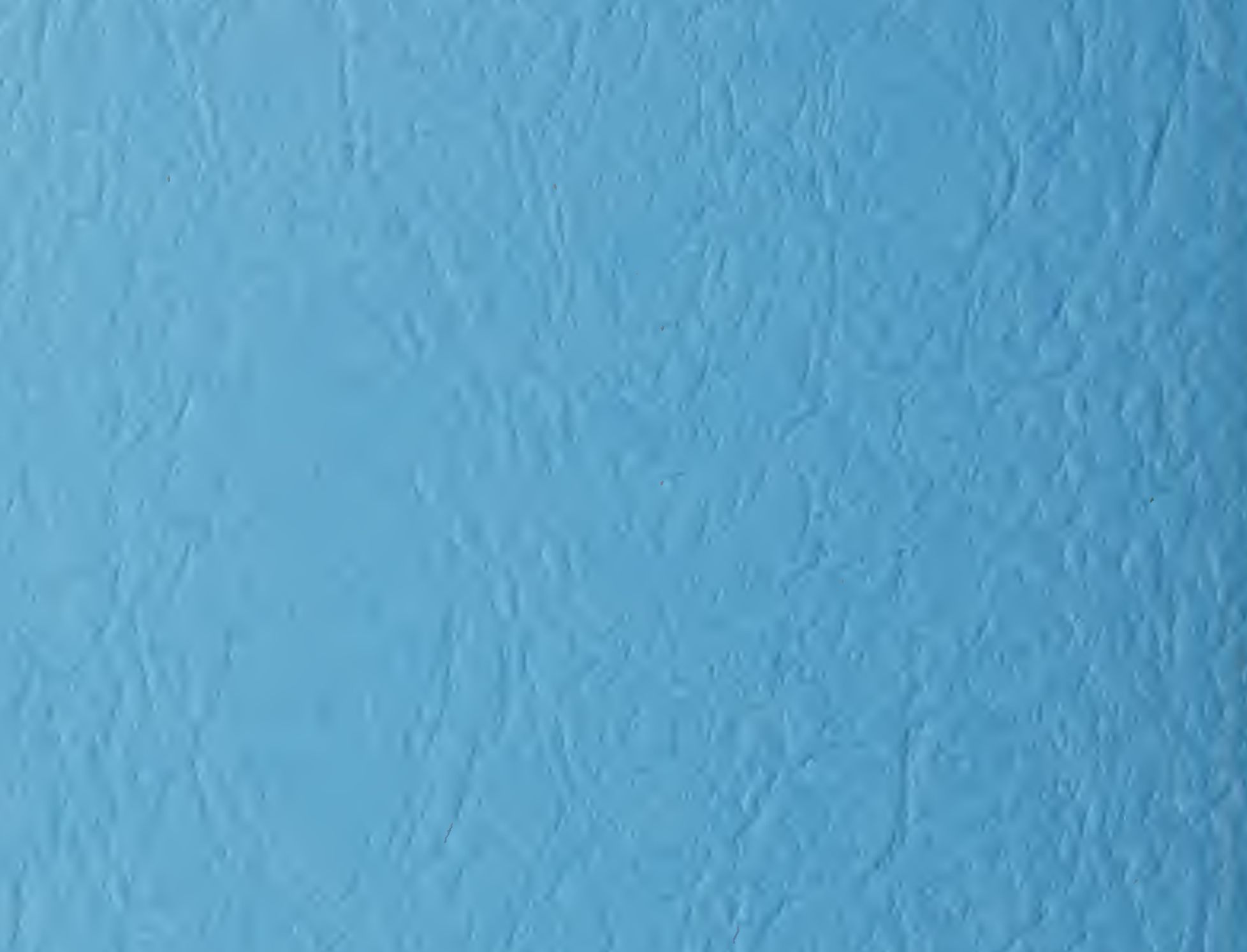

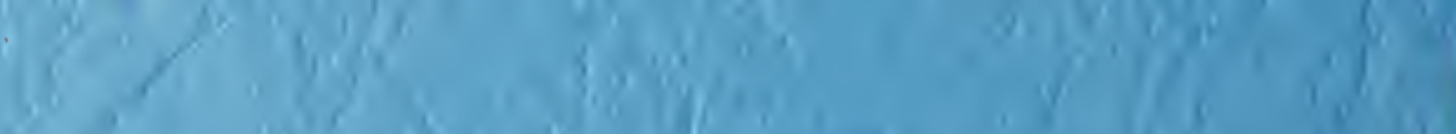

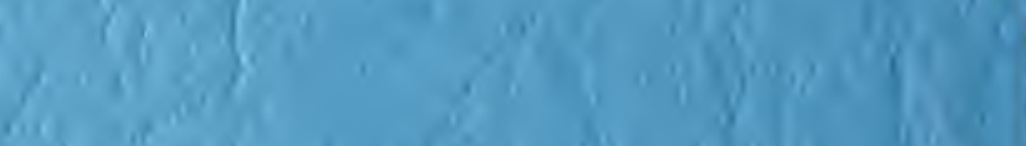

1

1.

i)

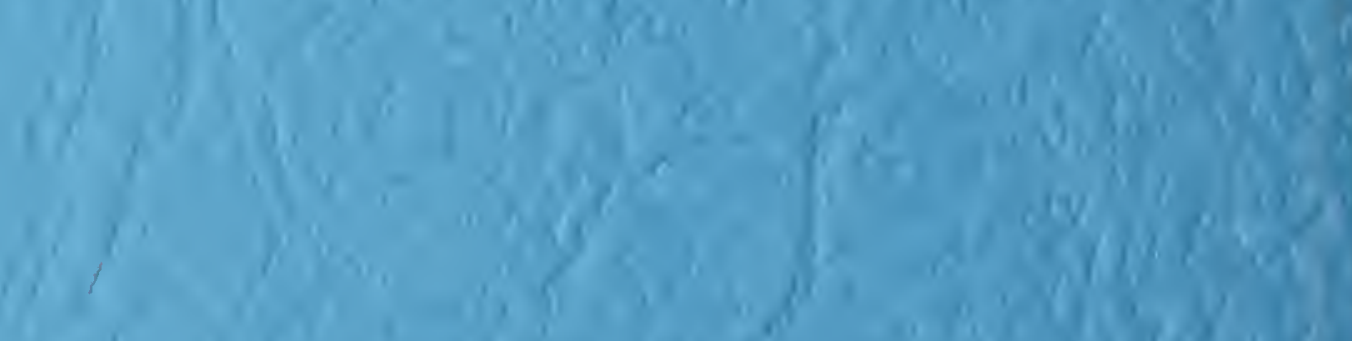

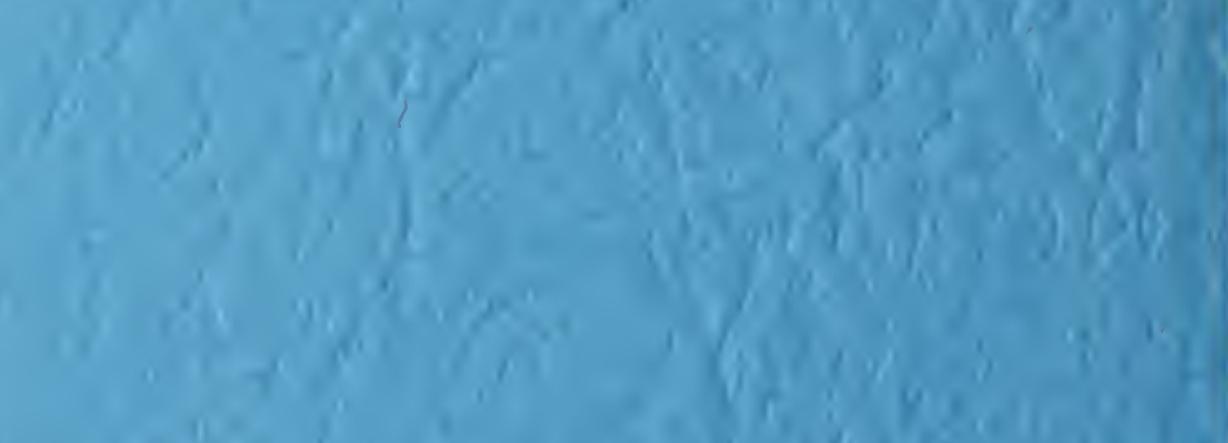

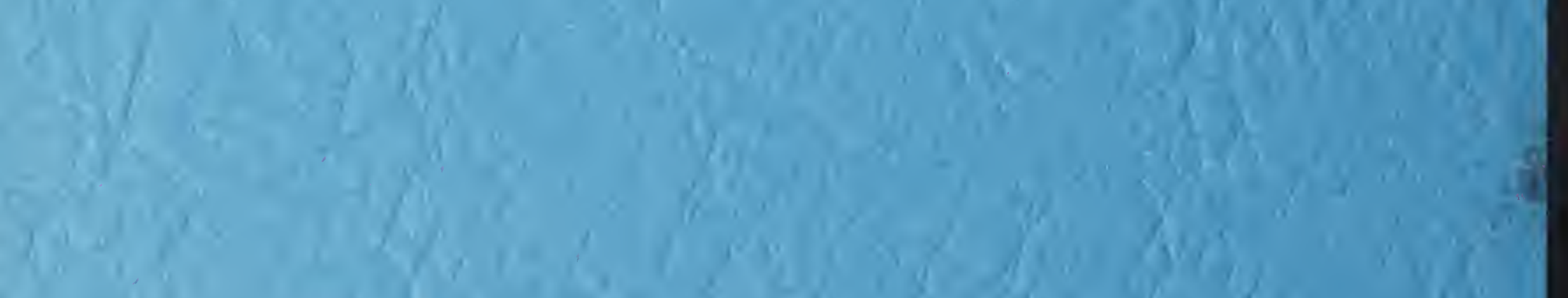

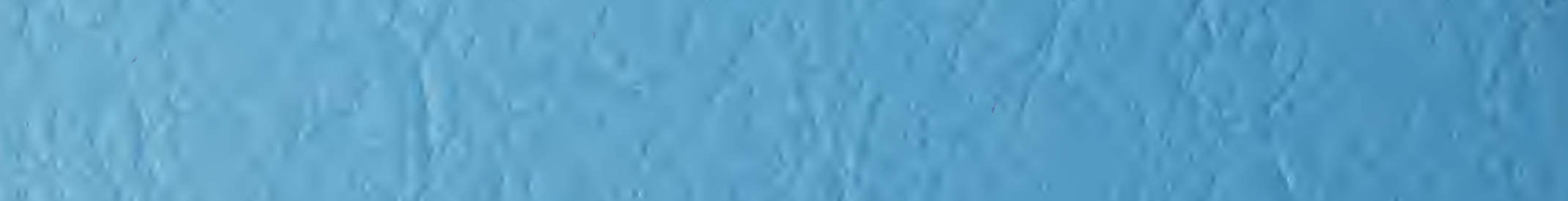

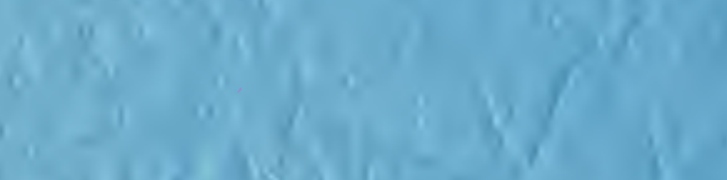

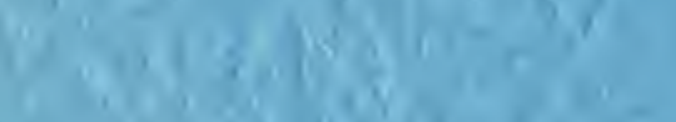

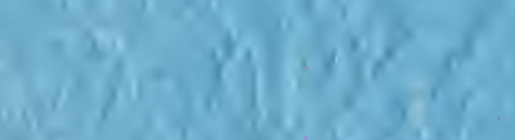

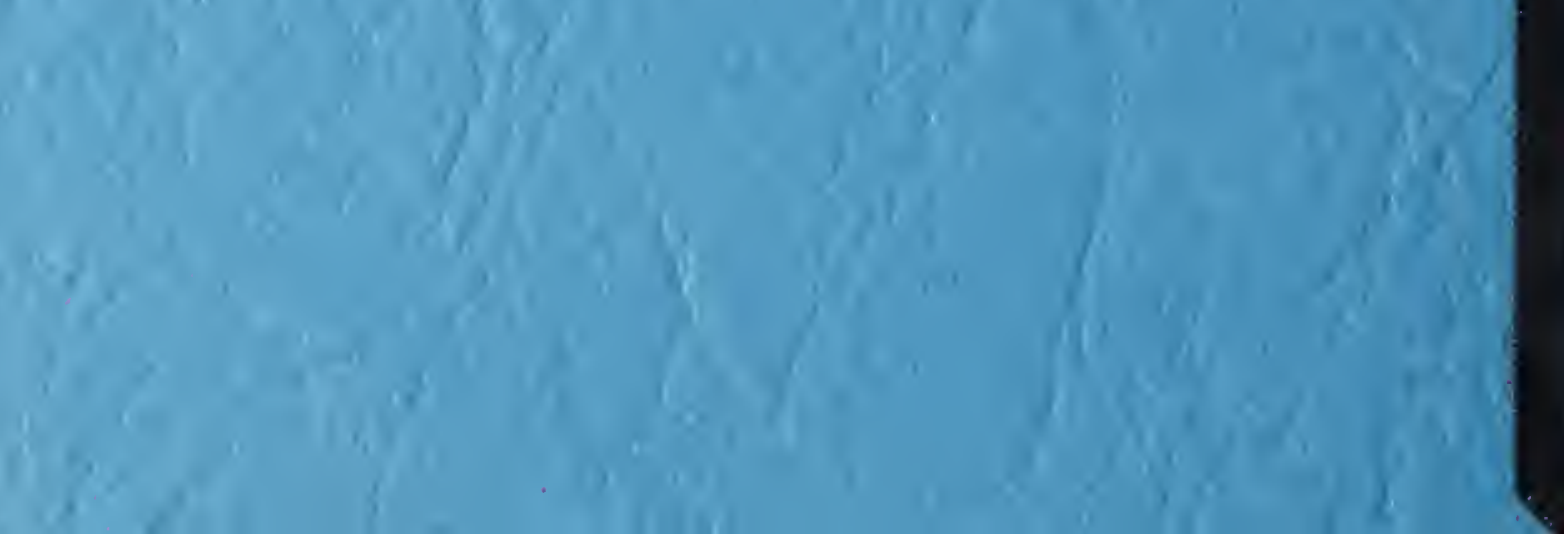

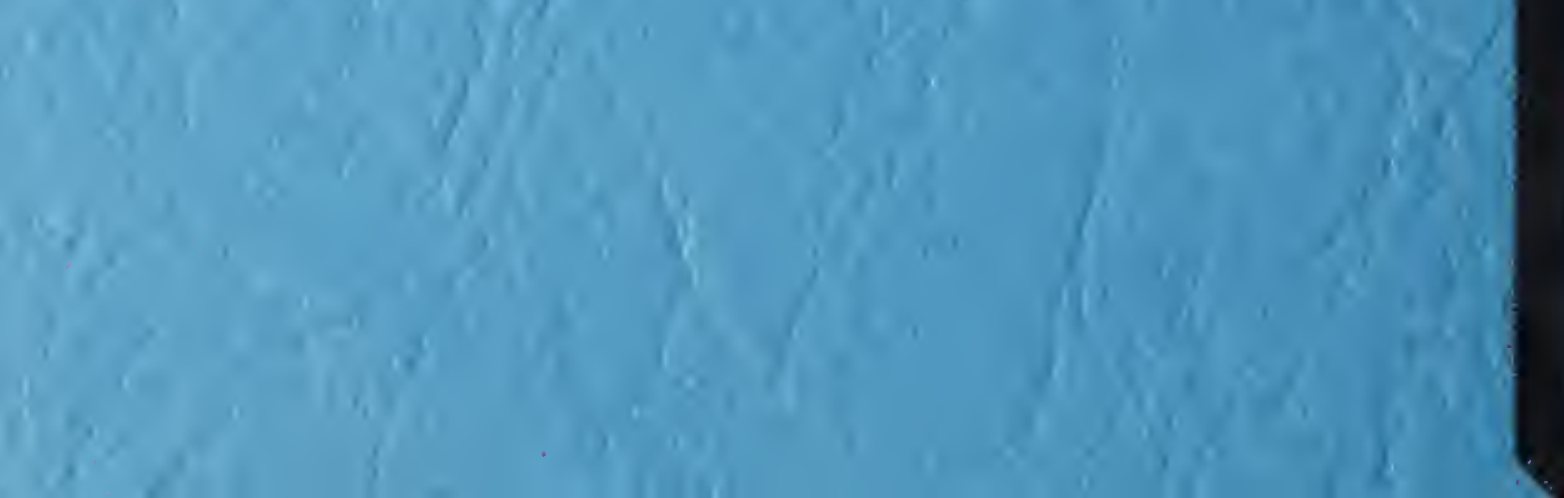

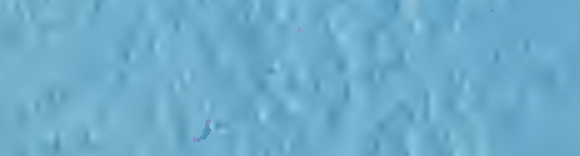

